\title{
Performance Comparisons of Selected Personnel Dosimetry Systems in Use at Department of Energy Facilities
}
P. L. Roberson
R. T. Hadley
K. L. Holbrook
B. T. Hogan
R. C. Yoder
C. D. Hooker
R. A. Fox

October 1983

Prepared for the U.S. Department of Energy under Contract DE-AC06-76RLO 1830

Pacific Northwest Laboratory Operated for the U.S. Department of Energy by Battelle Memorial Institute 


\title{
DISCLAIMER
}

This report was prepared as an account of work sponsored by an agency of the United States Government. Neither the United States Government nor any agency thereof, nor any of their employees, makes any warranty, express or implied, or assumes any legal liability or responsibility for the accuracy, completeness, or usefulness of any information, apparatus, product, or process disclosed, or represents that its use would not infringe privately owned rights. Reference herein to any specific commercial product, process, or service by trade name, trademark, manufacturer, or otherwise, does not necessarily constitute or imply its endorsement, recommendation, or favoring by the United States Government or any agency thereof. The views and opinions of authors expressed herein do not necessarily state or reflect those of the United States Government or any agency thereof.

\author{
PACIFIC NORTHWEST LABORATORY \\ operated by \\ BATTELLE \\ for the \\ UNITED STATES DEPARTMENT OF ENERGY \\ under Contract DE-AC06-76RLO 1830
}

\begin{tabular}{|c|c|}
\hline \multicolumn{2}{|c|}{ Printed in the United States of America } \\
\hline \multicolumn{2}{|c|}{ Available from } \\
\hline \multirow{3}{*}{\multicolumn{2}{|c|}{$\begin{array}{c}\text { National Technical Information Service } \\
\text { United States Department of Commerce } \\
5285 \text { Port Royal Road } \\
\text { Springfield, Virginia } 22161\end{array}$}} \\
\hline & \\
\hline & \\
\hline \multirow{2}{*}{\multicolumn{2}{|c|}{$\begin{array}{l}\text { NTIS Price Codes } \\
\text { Microfiche A01 }\end{array}$}} \\
\hline & \\
\hline \multicolumn{2}{|c|}{ Printed Copy } \\
\hline & Price \\
\hline Pages & Codes \\
\hline $001-025$ & $\mathrm{~A} 02$ \\
\hline $026-050$ & $\mathrm{~A} 03$ \\
\hline $051-075$ & $\mathrm{~A} 04$ \\
\hline $076-100$ & A05 \\
\hline $101-125$ & $\mathrm{~A} 06$ \\
\hline $126-150$ & $\mathrm{~A} 07$ \\
\hline $151 \cdot 175$ & A08 \\
\hline $176-200$ & A09 \\
\hline $201-225$ & $A 010$ \\
\hline $226-250$ & $A 011$ \\
\hline $251-275$ & $\mathrm{~A} 012$ \\
\hline $276-300$ & $A 013$ \\
\hline
\end{tabular}


PERFORMANCE COMPARISONS OF SELECTED PERSONNEL DOSIMETRY SYSTEMS IN USE AT DEPARTMENT OF ENERGY FACILITIES

P. L. Roberson

K. L. Holbrook (a)

R. C. Yoder $(b)$

R. A. Fox

R. T. Hadley

B. T. Hogan

C. D. Hooker

October 1983

Prepared for the U.S. Department of Energy under Contract DE-AC06-76RLO 1830

Pacific Northwest Laboratory Richland, Washington 99352

(a) University of Texas Hospital Galveston, TX 77550

(b) R. S. Landauer, Jr., \& Company Glenwood Science Park

Glenwood, IL 60425 


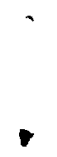

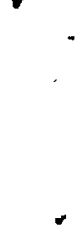


This work is part of the research project "Technical Guidelines for Personnel Dosimetry Calibrations" performed by the Pacific Northwest Laboratory for the Office of Nuclear Safety, Office of Environmental Protection, Safety and Emergency Preparedness, Department of Energy (DOE). The purpose of the project is to develop guidelines for radiological calibrations of personnel dosimeters and radiation protection instruments used at DOE facilities. A data base was developed on the performance of DOE personnel dosimetry systems through a voluntary testing program. This report contains the data collected. 
. 
Dosimeter performance data were collected to help develop a uniform approach to the calibration and use of personnel dosimetry systems for Department of Energy (DOE) laboratories. Eleven DOE laboratories participated in six months of testing using the American National Draft Standard, Criteria for Testing Personnel Dosimetry Performance, ANSI N13.11, and additional testing categories. Dosimeters were shipped to the Pacific Northwest Laboratory (PNL) for irradiation and returned. The data was collected in three phases:

(I) ANSI N13.11 tests using participant calibrations; (II) ANSI N13.11 tests using PNL calibrations; and (III) additional radiation type and energy studies using PNL calibrations.

The tests described in ANSI N13.11 used a pass/fail system to determine compliance with the draft standard. While scoring the results had little meaning for the present study, it did provide a summary of performance. Two laboratories participated in only a subset of the ANSI tests and passed all categories attempted. However, the greatest difficulty encountered was passing the ${ }^{137} \mathrm{Cs}, x$-ray, and ${ }^{90} \mathrm{Sr} /{ }^{90} Y$ categories in the same test. It was much easier to have a good performance if only a subset was entered. The number of participants (Phase I) passing ten, nine, eight, seven, and six of all ten tests were two, one, two, one, and three, respectively.

Recalculation to PNL irradiations (Phase II) showed that the ${ }^{137} \mathrm{Cs}$, ${ }^{90} \mathrm{Sr} /{ }^{90} \mathrm{Y}$, and ${ }^{252} \mathrm{Cf}$ categories can be recalibrated to have acceptable performance for nearly all participant systems. Deficient dosimeter design or handling techniques caused poor performance in the $x$-ray category for nearly half of the participants. Too little filtration for the deep-dose element caused poor performance in the beta/photon mixture category for one participant. Two participants had excessively high standard deviations in the neutron category due to dosimeter design or handling deficiencies. The number passing ten, nine, eight, and seven of ten tests were two, two, three, and one, respectively. 
The participating dosimetry systems were separated into three categories on their dose evaluation procedure for low-energy photons. These were film dosimeters, fixed-calibration thermoluminescent (TL) dosimeters, and variablecalibration TL dosimeters. The variable-calibration designs depended on the relationship between sensitive elements to modify the dose calculation. The performance of the variable-calibration design was best while the film dosimeters performed considerably worse than either $\mathrm{TL}$ dosimeter design.

Beta energy dependence studies confirmed a strong correlation between sensitive element thickness, shallow element filtration and low-energy beta response. Studies of neutron calibration conditions for each participant suggested a relationship between response and calibration facility design.

The performance data was used to analyze draft ANSI N13.11 as a standard for DOE. Several deficiencies in the draft standard were found. The predominant reason for the deficiencies was that the standard was written to apply to a general audience of large and small processors. The deficiencies noted are:

- Additional performance tests are required for a sufficient evaluation.

- The performance algorithm is not the optimal choice for implementing the performance standard.

- The design of the beta category can lead to ambiguous results.

- The conversion factors from exposure to dose for low-energy photons are inconsistent with the irradiating geometry. 


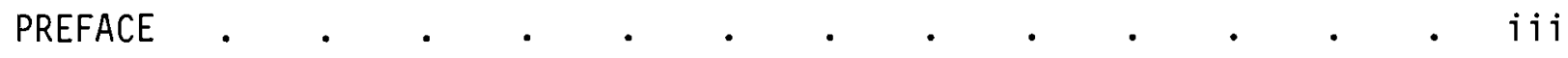

SUMMARY

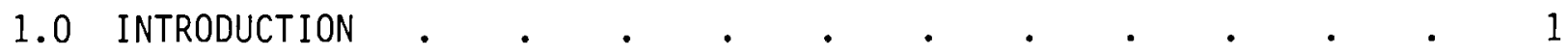

2.0 DESIGN OF PERFORMANCE TESTS . 0 . . . . . . . . . . . . 3

3.0 TEST PROCEDURES $\quad$. 5 .

3.1 DOSIMETER HANDLING PROCEDURES • • • • • • •

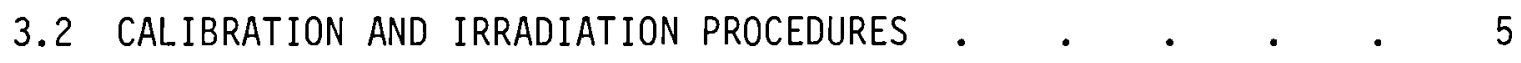

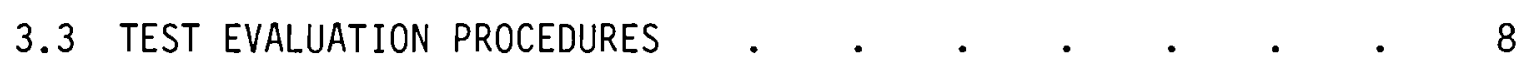

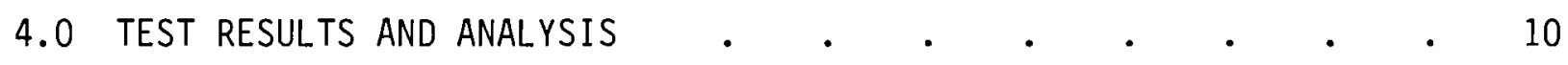

4.1 DOSIMETER PERFORMANCE TEST (ANSI N13.11) $\quad$ • $\quad . \quad$ • 10

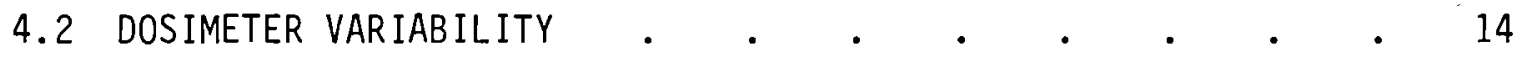

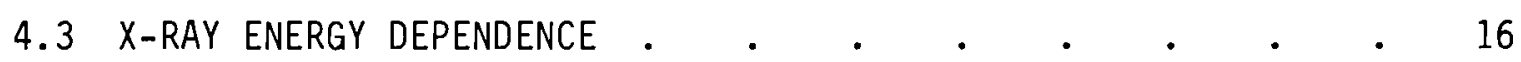

4.4 BETA ENERGY DEPENDENCE AND CALIBRATION EFFECTS $\quad$ • . $\quad$ • 23

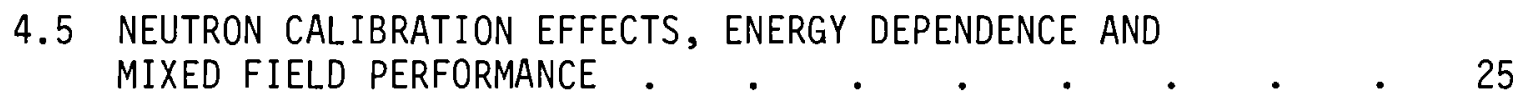

\begin{tabular}{l}
4.6 EVALUATION OF DOSIMETER PERFORMANCE BASED ON OTHER \\
EXISTING STANDARDS \\
\hline
\end{tabular}

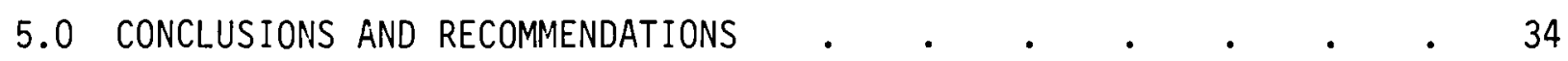

5.1 EVALUATION OF DOSIMETER PERFORMANCE USING THE ANSI N13.11

PERFORMANCE CRITERIA

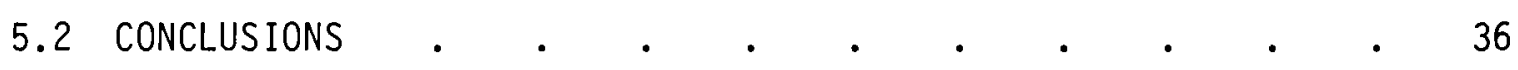

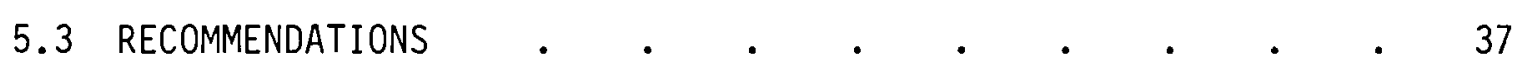

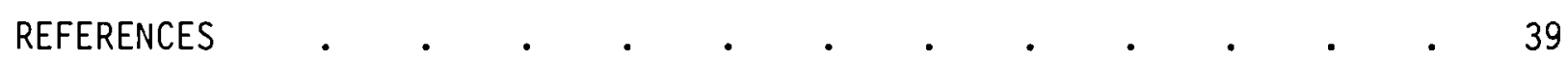

APPENDIX A - COMPILATION OF DOSIMETER PERFORMANCE DATA . • . . . A.1

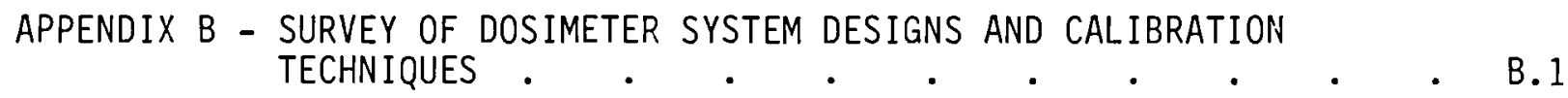




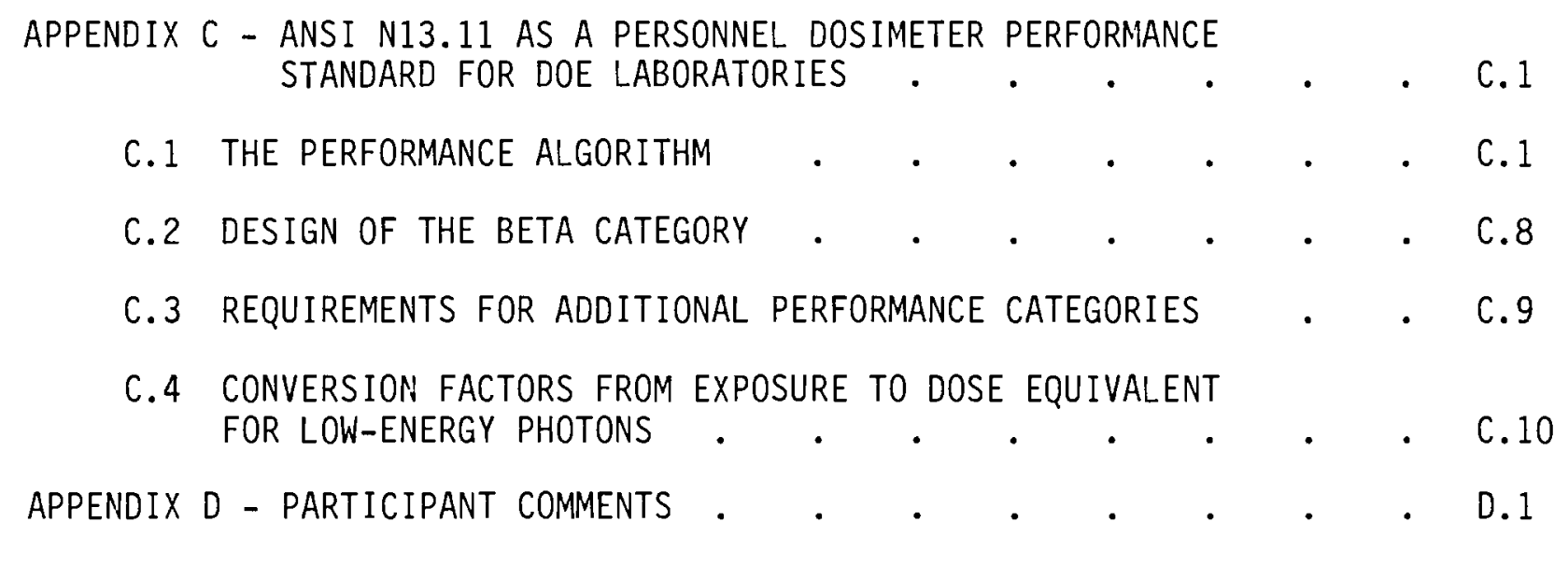




\section{FIGURES}

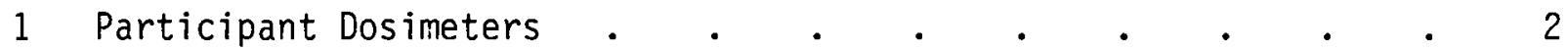

2 Summary of Phase I Performance (Participant Calibrations) . . 11

3 Summary of Phase II Performance (PNL Calibrations) $\quad$ e $\quad$ e $\quad 12$

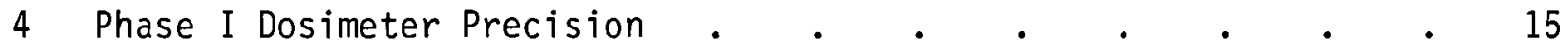

$5 \quad X$-Ray Shallow Dose Performance of TL Dosimeters

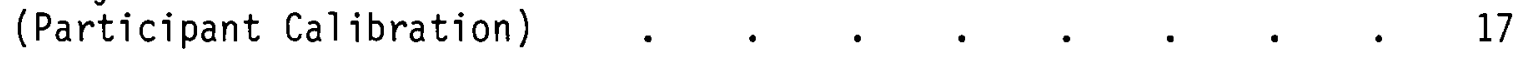

6 X-Ray Deep Dose Performance of TL Dosimeters

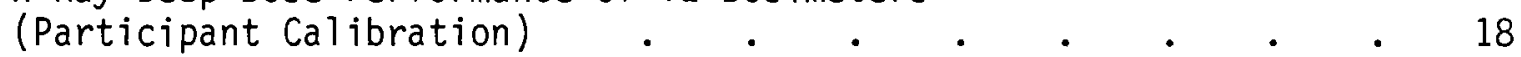

$7 \quad X$-Ray Shallow Dose Performance of TL Dosimeters (Recalibrated Based on PNL Irradiations) $\quad . \quad$. $\quad . \quad$. 19

8 X-Ray Deep Dose Performance of TL Dosimeters (Recalibrated Based on PNL Irradiations) . . . . . . 20

9 X-Ray Performance of Film Dosimeters (Shallow Dose) . • . $\quad 21$

10 X-Ray Performance of Film Dosimeters (Deep Dose) . . . . 22

11 Low-Energy Beta Response $\left({ }^{85} \mathrm{Kr} /{ }^{90} \mathrm{Sr}-{ }^{90} \mathrm{Y}\right)$. . . . . . . 24

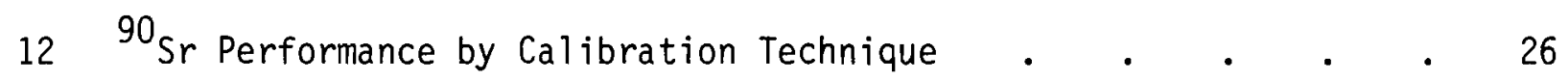

13 TL-Albedo Dosimeter Performance as a Function
of Calibration Facility Scatter . . . . . . . 28 


\section{$\underline{T A B L E S}$}

1 Irradiation Categories for the Performance Testing of

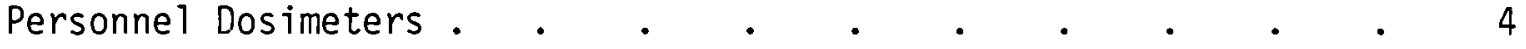

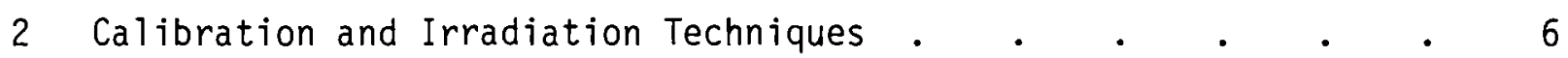

3 Dosimeter Response to Moderated ${ }^{252} \mathrm{Cf}$, Relative to Unmoderated $252 \mathrm{CF}$.

4 Estimated Additive Bias for Film Dosimeters . . . . . . . 31

5 Estimated Multiplicative Bias for Film Dosimeters . . . . . 31

6 Bias Criteria for Film Dosimeters . . . . . . . . . 32

7 Dosimeter Performance Using ANSI N13.11 Performance Criteria . 35

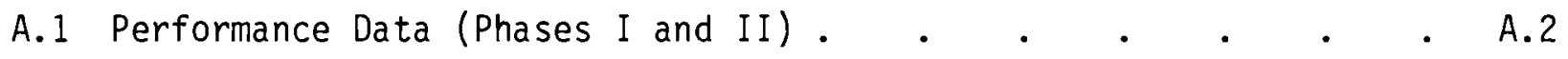

A.2 Performance Data (Phase III, May) . . . . . . . . . A.8

A.3 Performance Data (Phase III, June) . . . . . . . . . . A.11

A.4 Performance Data (Phase III, July) . . . . . . . . . . A.14

B.1 Participant Summary of Beta-Gamma Dosimetry Practices . . . B.2

B.2 Participant Summary of Neutron Dosimetry Practices . . . B.3

C.1 Estimates of (Zero-Bias) Standard Deviations . . . . . . C.4

C.2 Maximum True Performance Values . . . . . . . . . . . C.5

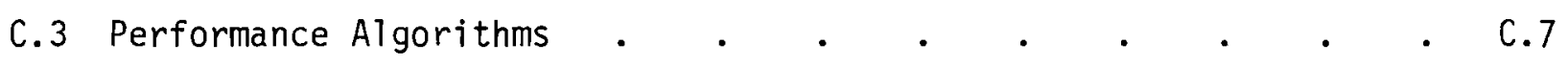

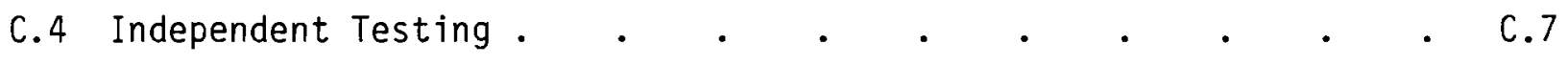




\subsection{INTRODUCTION}

The data described in this report were collected to form a base of information on the performance of personnel dosimeters in use at DOE facilities. This information will aid the formulation of optimal dosimeter calibration techniques. Standardized calibration techniques based on national dosimetry standards will aid the efforts for uniform assignment of dose or dose equivalent for occupationally exposed workers.

The performance data are the result of irradiations of DOE laboratory personnel dosimeters under test conditions. The irradiations were performed at the PNL and the National Bureau of Standards (NBS). The DOE laboratories that participated in the study were:

- Argonne National Laboratory (ANL)

- Brookhaven National Laboratory (BNL)

- Idaho National Engineeering Laboratory (INEL)

- Lawrence Livermore National Laboratory (LLNL)

- Mound Facility

- Nevada Test Site - Reynolds Electric Company (REECo)

- Pantex Facility

- Pacific Northwest Laboratory (Hanford)

- Rocky Flats Plant - Rockwell International

- Sandia National Laboratories

- Savannah River Plant (SRP).

The dosimeters used are shown in Figure 1.

The dosimeter testing was done concurrently with testing for the Personnel Neutron Dosimeter Upgrade and Evaluation Program. This data is reported in Response Characteristics of Selected Personnel Neutron Dosimeters (McDonald, et al. 1983). 


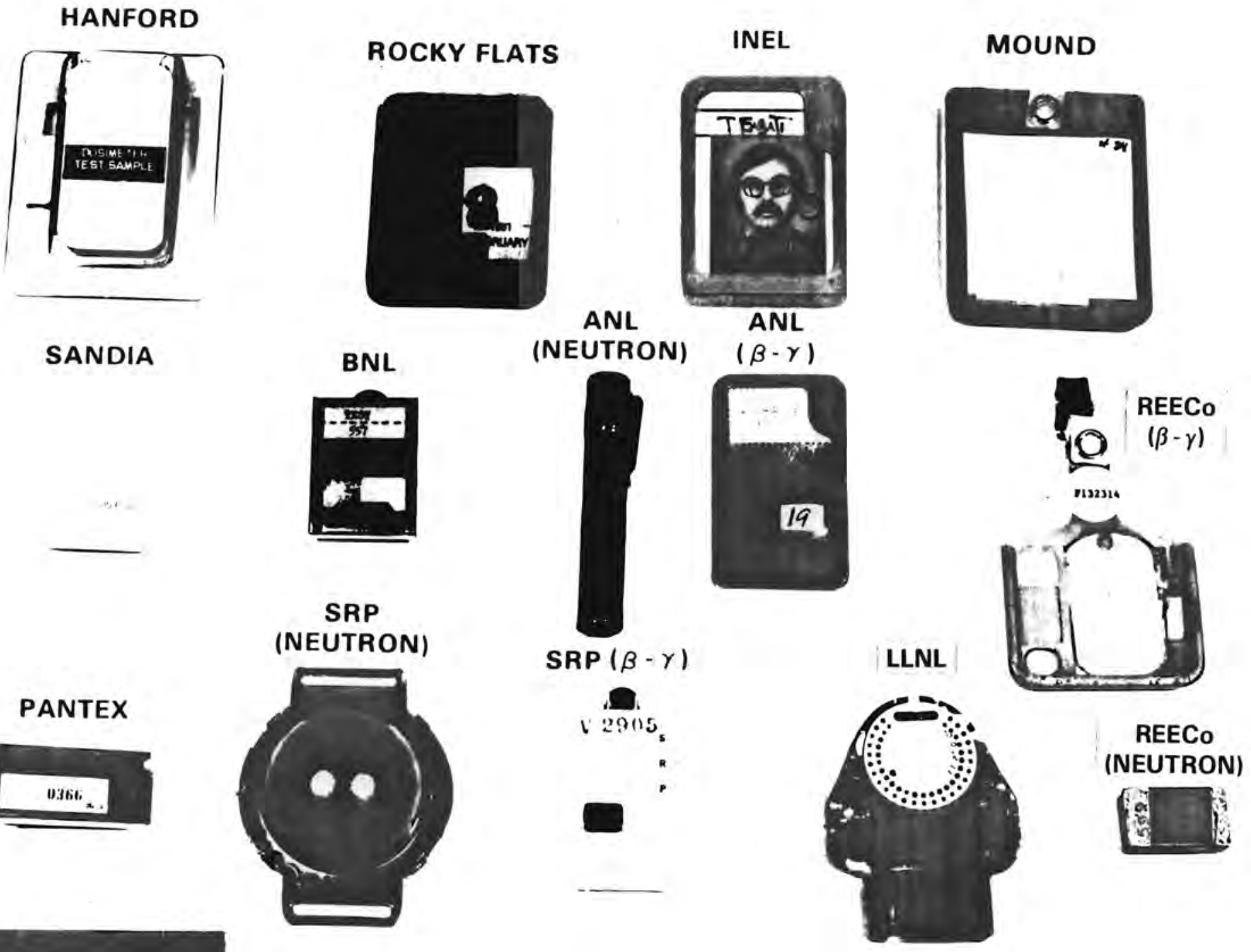

FIGURE 1. Participant Dosimeters 


\subsection{DESIGN OF PERFORMANCE TESTS}

The performance tests were based on a draft of the American National Standard N13.11, "Criteria for Testing Personnel Dosimetry Performance," (ANSI 1978). Because of the limited scope of the performance tests given in the standard, further testing was performed to investigate the photon and beta energy dependence of the dosimeters and the effects of $x$-ray/neutron mixtures.

The 1978 draft of ANSI N13.11 differs from the adopted version (ANSI 1983) in several respects. Exposure-to-dose-equivalent conversion factors were revised. The unmoderated ${ }^{252} \mathrm{Cf}$ category used in the test program was removed from the standard, and a mixture of moderated ${ }^{252} \mathrm{Cf}$ with ${ }^{137} \mathrm{Cs}$ photons was included. To account for the changes, the assigned (delivered) dose equivalents used in the test were modified, and moderated ${ }^{252} \mathrm{Cf}$ irradiations were performed during the final phase of testing.

The performance tests were divided into three phases. Phase I consisted of a test sequence similar to that specified in ANSI N13.11 (dosimeter sets for February, March, and April in Table 1). In Phase II, the participants were given calibration information (dosimeter sets for May) and asked to reevaluate the first three data sets. This provided information on the dependence of dosimeter performance on the calibration methods. In Phase III, dosimeter performance for sources not included in ANSI N13.11 was investigated (dosimeter sets for May, June, and July). Dosimeter reports for Phase III used the May calibration information. Energy response in the $x$-ray region was determined using four filtered $x$-ray techniques and two k-fluorescent $x$-ray techniques. Beta-particle energy response was determined by comparing the dosimeter response for ${ }^{85} \mathrm{Kr}\left(0.67 \mathrm{MeV}\right.$ maximum) to ${ }^{90} \mathrm{Sr}^{90}{ }_{\mathrm{Y}}$ (approximately $2 \mathrm{MeV}$ maximum with filtration). The neutron spectrum dependence was determined using a moderated ${ }^{252} \mathrm{Cf}$ irradiation provided by NBS. Dosimeter response to a mixed $x$-ray and neutron field was also tested.

The performance testing was limited to whole-body personnel dosimeters used for estimating dose equivalent received for the permanent record. The dosimeters were exposed to levels consistent with routine health protection only. Accident-level doses were not included. 
TABLE 1. Irradiation Categories for the Performance Testing of Personnel Dosimeters

\section{Dosimeter Set(s)}

February, March, Apri 1

(Phase I and II)

May (Phase I and II)

June (Phase III)

July (Phase III)

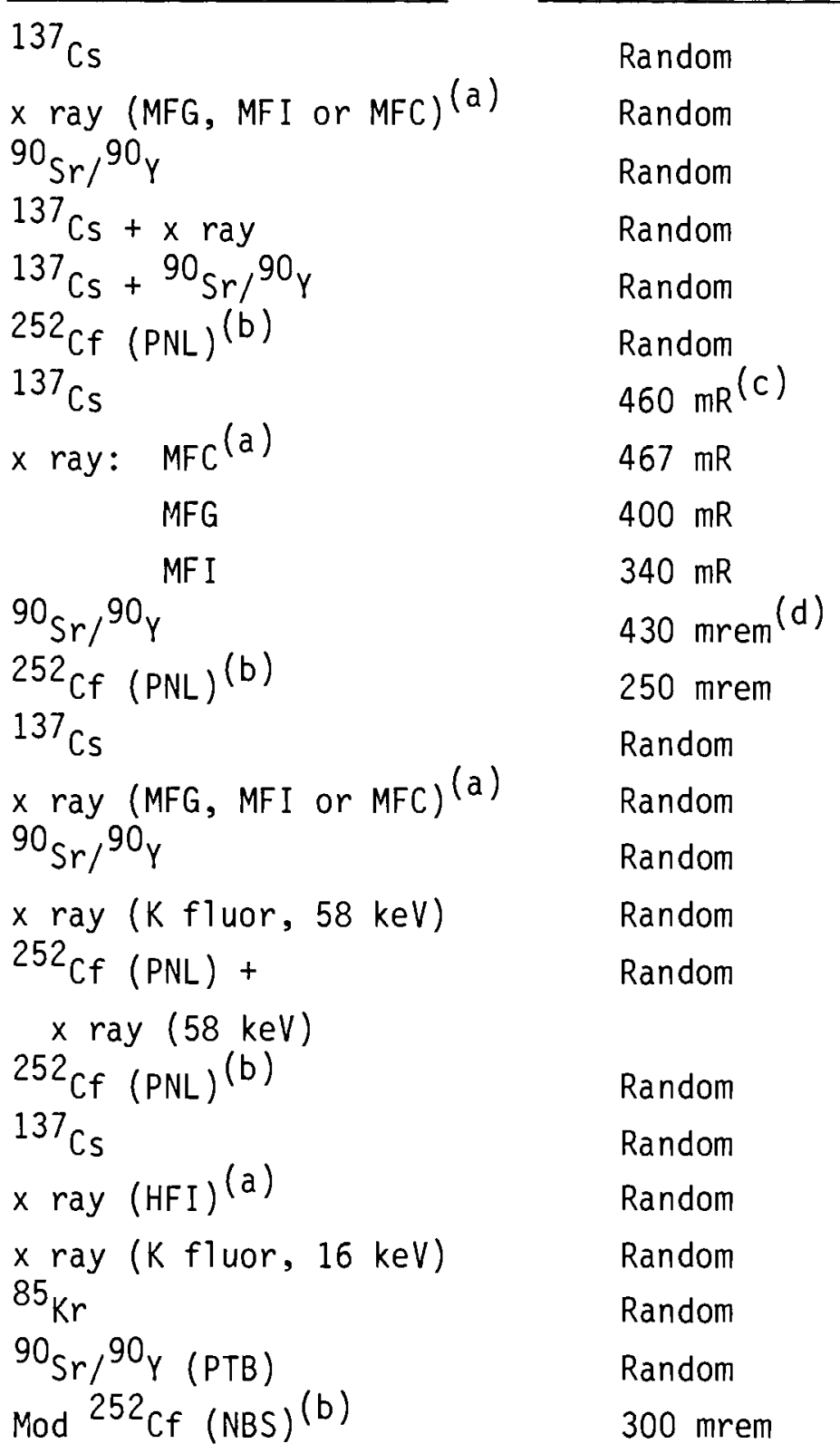

Categories

Nominal

Exposure or Dose

Random

Random

$460 \mathrm{mR}^{(\mathrm{c})}$

$467 \mathrm{mR}$

$340 \mathrm{mR}$

(d)

$90_{\mathrm{Sr} /}{ }^{90} \mathrm{Y}$

${ }^{252} \mathrm{Cf}(\mathrm{PNL})(\mathrm{b})$

${ }^{137} \mathrm{Cs}$

$x \operatorname{ray}(M F G, M F I$ or $M F C)(a)$

(a) NBS Special Publication 250 Appendix (NBS 1981).

(b) Shared with DOE Neutron Program (McDonald et al. 1983).

(c) The exposure to deliver 500 mrem was calculated using conversion factors from an earlier version of (draft) ANSI N13.11.

(d) A calibration error for the beta sources was found after $90_{\mathrm{Sr}} / 90_{\mathrm{Y}}$ (PTB) values, required a multiplicative correction factor of 0.86 . 


\subsection{TEST PROCEDURES}

\subsection{DOSIMETER HANDLING PROCEDURES}

The participating laboratories shipped to PNL 30 dosimeters plus controls per irradiation set (approximately one per month). Five dosimeters were irradiated per category. All dosimeters awaiting irradiation or shipping were stored in the same low-background area. The control dosimeters remained in the storage area while the irradiations were performed. Irradiations were performed in sets of four dosimeters when possible, using no two from the same laboratory. The five dosimeters of each category were irradiated separately. A suspected misirradiation could be checked by comparing dosimeter results from other laboratories. The exception were late shipments of dosimeters. Dosimeters missing the scheduled irradiations were irradiated together in groups of 2 and 3.

One category of the July set was sent to NBS to obtain irradiations using a heavy-water moderated ${ }^{252} \mathrm{Cf}$ source (described in Schwartz and Eisenhauer 1980). At least two control dosimeters accompanied the test dosimeters.

The exchange rate was designed to be a dosimeter set per month. The exchange period was significantly exceeded in several cases due to late receipt of dosimeter sets and/or the construction schedule for the PNL calibration areas. Results of some of the NTA film dosimeters were lost due to inadequate attention to the constant requirement for dessicant. Excessive moisture resulted in accelerated fading of the dosimeter response.

\subsection{CALIBRATION AND IRRADIATION PROCEDURES}

The source calibration procedures are described in a companion report, Facilities and Procedures Used for Performance Testing of DOE Personnel Dosimetry Systems (PNL-4207, Roberson, et a1. 1983).

A summary of calibration and irradiation techniques is presented in Table 2. The photon sources were calibrated for exposure in air. Doses were calculated using the conversion factors given in the adopted version of ANSI N13.11 (ANSI 1982). A change in the exposure-to-dose conversion factors between drafts of ANSI $N 13.11$ shifted the May ${ }^{137}$ Cs calibration from 500 mrem to $473 \mathrm{mrem}$. 
TABLE 2. Calibration and Irradiation Techniques

\begin{tabular}{|c|c|c|c|c|}
\hline Source & $\begin{array}{l}\text { Calibration } \\
\text { Method }\end{array}$ & Rem & $\begin{array}{l}\text { Conversion } \\
\text { Factor }\end{array}$ & Irradiation Geometry \\
\hline${ }^{37} \mathrm{Cs}$ & Exposure in Air & ANSI & N13.11 & $\begin{array}{l}\text { On phantom } \\
\text { Source to phantom surface }=1 \mathrm{~cm} \times 30 \mathrm{~cm} \times 15 \mathrm{~cm} \text { phantom }\end{array}$ \\
\hline
\end{tabular}

$X$ Ray Exposure in Air ANSI N13.11

Beta Absorbed Dose at $\quad 1.00$ at $0.007 \mathrm{~cm}$

a

${ }^{252} \mathrm{Cf} \quad$ Emission Rate

Moderated Emission Rate $252 \mathrm{Cf}$

(a) Methylmethacrylate.

ANSI N13.11

tions
On phantom $(a)=30 \mathrm{~cm} \times 30 \mathrm{~cm} \times 15 \mathrm{~cm}$ phantom

Source to surface $=1 \mathrm{~m}$ (filtered techniques)

$50 \mathrm{~cm}$ (K-fluorescent techniques)

On phantom $(\mathrm{a})=30 \mathrm{~cm} \times 30 \mathrm{~cm} \times 15 \mathrm{~cm}$ phantgm $^{\text {han }}$

Source to phantom surface $=50.5 \mathrm{~cm}\left({ }_{85} \mathrm{Sr} /{ }^{98} \mathrm{Y}\right)$

$\begin{array}{ll}=50 & \mathrm{~cm} \\ =50 & \mathrm{~cm}\left({ }^{85} \mathrm{Kr}\right) \\ \left.{ }_{\mathrm{Sr}}{ }^{90} \mathrm{Y}, \text { PTB }\right)\end{array}$

Filtration $=100 \mathrm{mg} / \mathrm{cm}^{2}$ (both $\mathrm{Sr}$ sources)

plus scatter

corrections

On phantom $=30 \mathrm{~cm} \times 30 \mathrm{~cm} \times 15 \mathrm{~cm}$ water-filled box Source to phantom surface $=50 \mathrm{~cm}$

Room size $=10 \mathrm{~m} \times 17 \mathrm{~m} \times 9 \mathrm{~m}$

Source position = approximately centered in room

$8.98 \times 10^{-6}$ mrem Irradiated at NBS

$-\mathrm{cm} \times 0.89$ plus on phantom $-30 \mathrm{~cm} \times 30 \mathrm{~cm} \times 15 \mathrm{~cm}$ water-filled box scatter correc-
Source to phantom surface $=50 \mathrm{~cm}$

Room size $=11.7 \mathrm{~m} \times 11 \mathrm{~m} \times 4.6 \mathrm{~m}$ with open ceiling Source position $=2.3 \mathrm{~m}$ above floor, approximately centered 
The beta sources were calibrated in terms of absorbed dose to tissue at a depth of $0.007 \mathrm{~cm}$. The filtration for the ${ }^{90} \mathrm{Sr} /{ }^{90} \mathrm{Y}$ sources was increased to approximately $100 \mathrm{mg} / \mathrm{cm}^{2}$ to comply with the ANSI specifications. An investigation of our beta calibration and its relationship to the beta-ray secondary standard calibrated by the PTB ${ }^{(a)}$ resulted in the discovery of a calibration error and a change in philosophy. After a discussion with NBS personnel concerning the discrepancy between PTB and NBS calibrations for ${ }^{90} \mathrm{Sr} /{ }^{90} \mathrm{Y}$ (approximately $5 \%$ ), they recommended that we use the PTB standards until NBS develops a comparable calibrations capability. To correct the ${ }^{90} \mathrm{Sr} /{ }^{90} \mathrm{Y}$ and ${ }^{85} \mathrm{Kr}$ calibrations to agree with the PTB standard, the given doses were multiplied by 0.86 .

The dose equivalent values assigned to dosimeters exposed to unmoderated ${ }^{252} \mathrm{Cf}$ were calculated using the NBS-measured neutron emission rate of the ${ }^{252} \mathrm{Cf}$ source and the conversion factor specified by an interim draft of ANSI N13.11. Corrections for the contribution of scattered neutrons were required. Following the calculational method suggested by NBS (Schwartz and Eisenhauer 1982), the reported fast neutron dose equivalents were divided by a scatter factor representing the increased response of dosimeters to the scattered neutrons. The estimated scatter factor at $50 \mathrm{~cm}$ for the PNL neutron irradiation room was 1.065 for albedo dosimeters and 1.01 for dose equivalent. The factor for albedo dosimeters was checked using measurements for the Hanford dosimeter.

The heavy-water moderated ${ }^{252} \mathrm{Cf}$ irradiations were performed at NBS. The formula used to determine the free-field dose equivalent was:

$$
\text { Dose Eq. Rate }=\frac{8.98 \times 10^{-6}}{4 \pi} \times 3600 \times 0.89 \frac{Q}{r^{2}}
$$

(a) The beta-ray secondary standard was calibrated at the PhysikalischTechnische Bundesanstalt (PTB), national bureau of standards for the Federal Republic of Germany. It is marketed by Buchler GmbH \& Co. It is composed of four beta sources, three with flattening filters, a support jig for a beta source with filter and a remote controller. The jig has a shutter allowing precise exposure timing. The sources were calibrated by the PTB for absorbed dose to tissue at depths between 0 and $1 \mathrm{~mm}$. 
where $Q$ is the source emission rate in neutrons per second, and $r$ is the source-to-phantom distance in $\mathrm{cm}$. The 0.89 factor allows for the loss of neutrons which are moderated below the cadmium cutoff. The conversion factor used to correct for the effects of scattered neutrons is 1.03. The fractional photon component was assumed to be 0.3 times the neutron dose equivalent.

The categories receiving randomized given exposures or dose equivalents are presented in Table 1 . The given values were linearly randomized between approximately $50 \mathrm{mrem}$ to $700 \mathrm{mrem}$. The upper limit was chosen to minimize irradiation times.

\subsection{TEST EVALUATION PROCEDURES}

The tests have been evaluated following the algorithm specified in ANSI N13.11 (1983). While the tests were not intended to be graded on a pass/fail system, maximum permissible values specified in ANSI N13.11 are included for reference. The performance algorithm used in ANSI N13.11 does not always provide a fair indication of performance (see Appendix $\mathrm{C}$ ), but was used for the test evaluations to be consistent with national standards. The algorithm is

$$
|B|+S \leq L
$$

where $B$ is the bias, $S$ is the standard deviation, and $L$ is the tolerance level. These quantities are defined as:

$$
\begin{aligned}
& B=\frac{1}{n} \sum_{i=1}^{n} P_{i} \\
& S=\left[\frac{1}{n-1} \sum_{i=1}^{n}\left(P_{i}-B\right)^{2}\right]^{\frac{1}{2}}
\end{aligned}
$$

and $L=0.5$ for the protection categories,

where

$$
P_{i}=\frac{\text { Reported }(i)-\text { Delivered }(i)}{\text { DeTivered }(i)}
$$


is the performance quotient for the $i^{\text {th }}$ dosimeter, $n=15$ for Phases I and II, and $n=5$ for Phase III. The performance criterion $(P C)$ is

$$
P C=|B|+S
$$




\subsection{TEST RESULTS AND ANALYSIS}

The dosimeter performance data are compiled in Appendix A. Dosimeter design and calibration techniques are summarized in Appendix $B$. These data are compiled to provide overviews of performance for the participating DOE laboratories. Results of testing according to ANSI N13.11 are summarized using the participant calibrations and the recalibrations to PNL irradiations. The bias, standard deviation and performance criterion are calculated for each category. Results of additional irradiations are shown according to dosimeter design and calibration method. X-ray energy dependence is shown by comparing the dosimeter bias for each $x$-ray technique. TL and film dosimeters are discussed separately, with the TL dosimeters further divided into fixed and variable calibration design. Significant differences in performance were observed for the three designs.

Beta energy dependence studies confirmed a strong correlation between TLD thickness, open window thickness, and low-energy beta response. Studies of neutron calibration conditions for each participant suggested a relationship between calibration facility design and performance in the unmoderated ${ }^{252} \mathrm{Cf}$ category. An analysis of dosimeter variability was performed to determine the effects of outliers on dosimeter performance.

\subsection{DOSIMETER PERFORMANCE TEST (ANSI N13.11)}

The performance test results for Phase I (based on participant calibrations) and Phase II (based on PNL calibrations) are given in Figures 2 and 3, respectively. Plotted are the bias, the standard deviation and the performance criterion for the categories tested. Data are given for shallow (S), deep (D), and fast-neutron $(F)$ dose equivalents. Data points which are off scale (positive) are plotted at the top for each parameter. A dotted line is placed at 0.5 for the performance criterion to represent the ANSI-N13.11 tolerance value.

For Phase I (Figure 2), the best performance is obtained for the ${ }^{137} \mathrm{CS}$ category. All standard deviations are less than 0.2 and the biases range between +0.2 and -0.3 . The performance for this category changes little from Phase I to Phase II (Figure 3). 

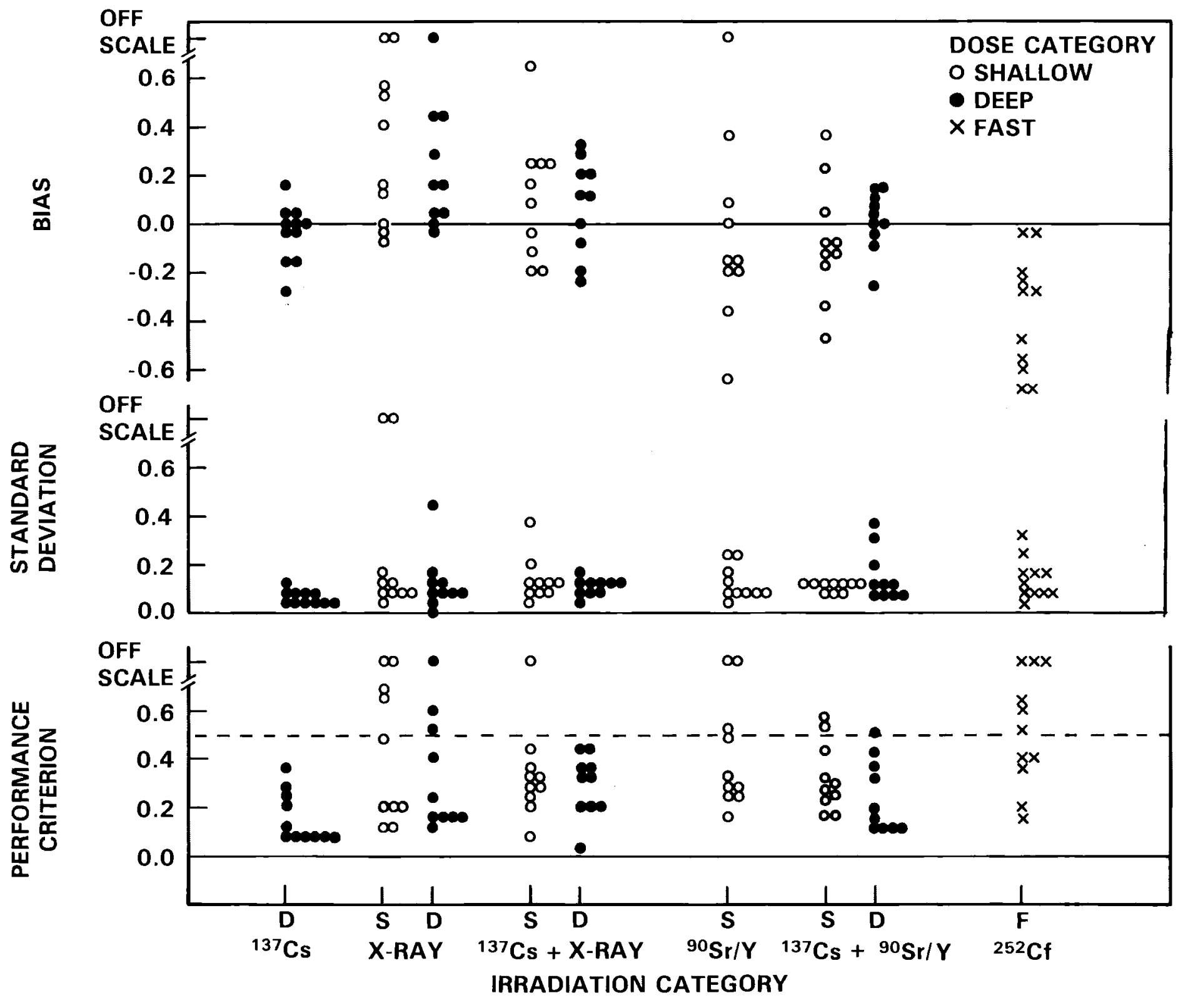

FIGURE 2. Summary of Phase I Performance (Participant Calibrations) 

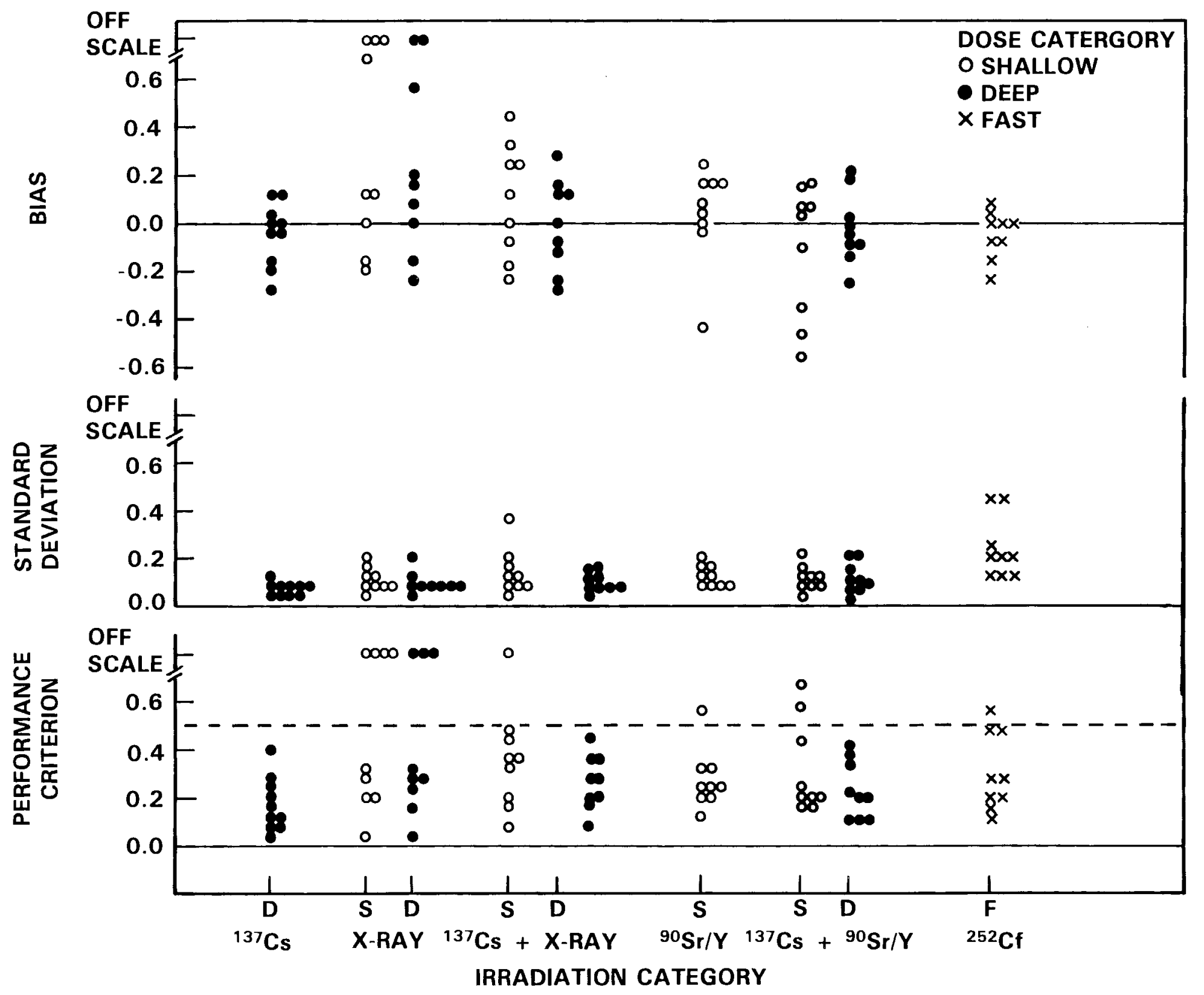

FIGURE 3. Summary of Phase II Performance (PNL Calibrations) 
Approximately half of the participating dosimetry systems overresponded to $x$ rays (i.e., large positive biases) in both Phase $I$ and Phase II. These overresponses were not corrected when the dosimetry systems were recalibrated. The quality of performance was limited by the dosimeter design and interpretation techniques used. Even though overall performance improved after recalibration, x-ray performance for approximately a quarter of the participant systems became worse. The shallow- and deep-dose performance displayed similar trends. The performance for the ${ }^{137}$ Cs plus $x$-ray mixture category was neither as good as for ${ }^{137} \mathrm{Cs}$ alone nor as poor as for $x$ rays alone.

The large standard deviations in the $x$-ray category for one of the participants were due to the performance algorithm. Because $S$ is proportional to $[1+B]$, a large bias produces a large standard deviation (see Appendix $C$ ). The ${ }^{90} \mathrm{Sr} /{ }^{90} \mathrm{Y}$ category shows a large spread in bias for Phase I. This was attributed to the various calibration techniques in use. In Phase II, nearly all of the participant systems were recalibrated to provide acceptable performance. Performance for the mixture category of ${ }^{137} C_{S}$ and ${ }^{90} \mathrm{Sr} /{ }^{90} \mathrm{Y}$ resembled the performance of its component categories, except for participant systems in which a significant deep dose was recorded for the ${ }^{90} \mathrm{Sr} /{ }^{90} \mathrm{Y}$ irradiations. This problem was present when the deep dose monitoring was done at effective depths less than approximately $400 \mathrm{mg} / \mathrm{cm}^{2}$. Because the system responded differently to the components of the mixture, which varied from a $3: 1$ to a $1: 3$ ratio, the deep-dose standard deviation was large.

The ${ }^{252}$ Cf category shows a large variation in bias for Phase I. A negative bias predominates because the calibration facilities in use typically have a lower-energy neutron spectrum than unmoderated ${ }^{252} \mathrm{Cf}$ in a low-scatter environment and because the TL albedo dosimeter has a greater response to lower-energy neutrons. Phase II shows that the systems can be successfully recalibrated. After recalibration two participant systems reported large standard deviations. The relative standard deviations were also high for Phase I, but were masked by the large negatively biased calibration. For a bias of less than $-0.5, S$ is less than one half its value for a calibrated system $(B=0)$. 
In summary, the Phase I and Phase II data showed that 1) the ${ }^{137} \mathrm{Cs}$, ${ }^{90} \mathrm{Sr} /{ }^{90} \mathrm{Y}$ and ${ }^{252} \mathrm{Cf}$ categories can be recalibrated to have acceptable performance for nearly all participant systems; 2) nearly half of the participant systems displayed deficient performance for $x$ rays; 3 ) one system showed a deficiency in the monitoring depth for the deep dose; and 4) two systems showed dosimeterdesign or handling deficiencies for the neutron category manifested in excessively high standard deviations.

\subsection{DOSIMETER VARIABILITY}

The dosimeter standard deviation in the ANSI N13.11 performance criteria provides an indirect indication of dosimeter variability. The standard deviation, as calculated from the bias, is proportional to dosimeter response. To allow a direct comparison of dosimeter variability among participants, the standard deviation defined in the performance criteria must be divided by one plus the dosimeter bias. For purposes of discussion, this quantity is referred to as dosimeter precision.

$$
\text { Precision }=\frac{S}{1+B}
$$

For a bias of zero, dosimeter precision is equal to the standard deviation.

Due to the small number of dosimeters used in calculating the standard deviation ( $n=15)$, a single extreme dosimeter reading (outlier) may result in unacceptable dosimeter precision and unacceptable performance in a category. To assess the effects of outliers, dosimeter results were recalculated after extreme values were discarded. Outliers were evaluated using a t-test at the 95\% confidence interval. For dosimeter results of February through April (Phases I and II), 15 dosimeters per category were pooled. For the special studies conducted in May through July, five dosimeters were pooled.

The effects of outliers are shown in Figure 4. Dosimeter precision is plotted for each category, using Phase I data (participant calibrations). Data sets which did not include extreme dosimeter readings are indicated by closed circles. Data sets of poor precision which contained single outliers are shown as open circles. Recalculated data sets excluding outliers are shown as 


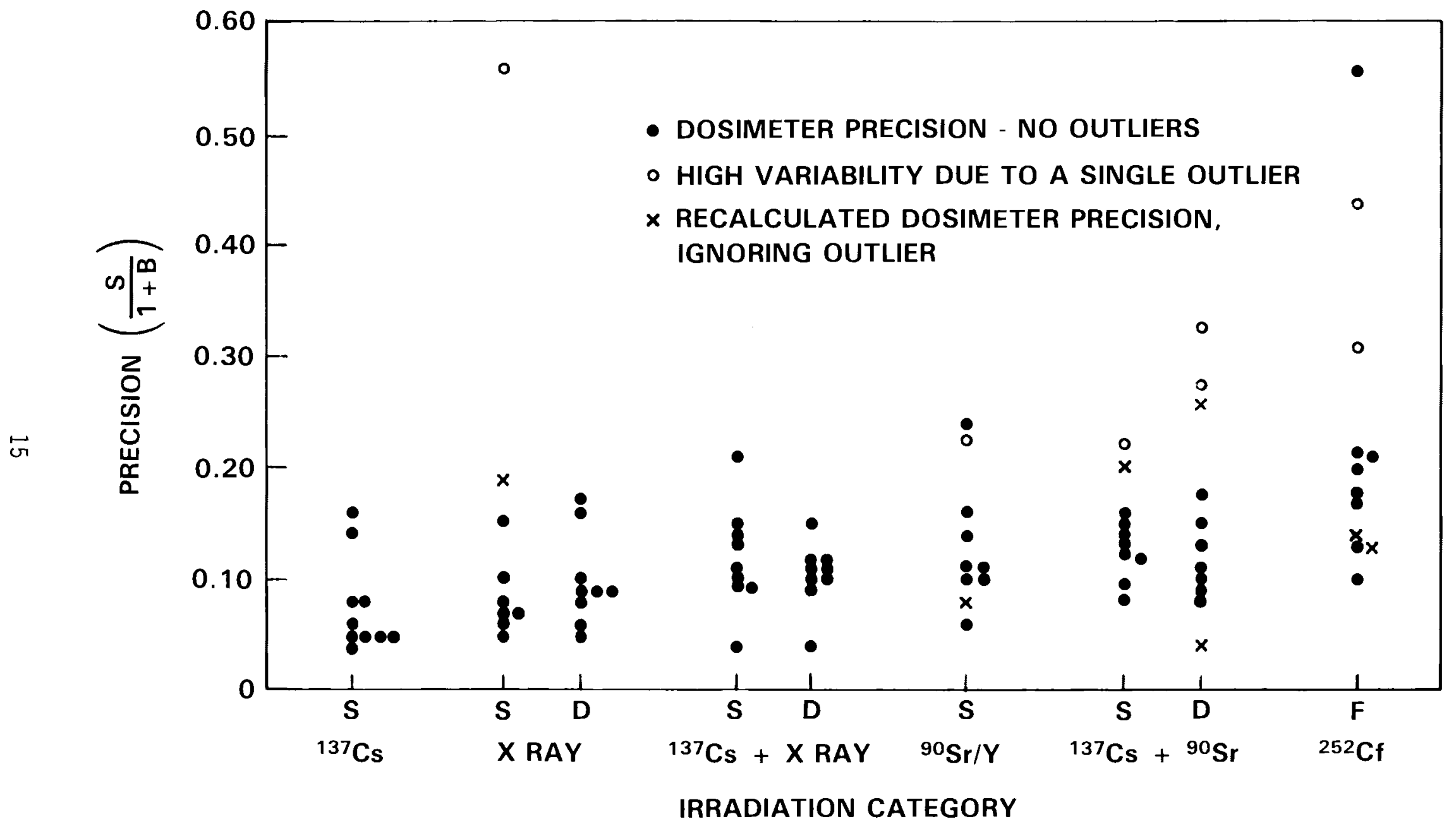

FIGURE 4. Phase I, Dosimeter Precision 
crossed symbols. For several data sets, the dosimeter precision did not change appreciably after recalculation. These results are shown by closed circles.

Most of the data sets with unacceptably high variability contained extreme dosimeter readings. After discarding outliers all participants with the exception of one laboratory showed a variability of $26 \%$ or less. The high variability in reported neutron doses for one laboratory was not due to a single isolated dosimeter reading, and should be investigated by the participant.

Although the impact of outliers was greatest in the $x$-ray shallow dose and neutron categories, the distribution of outliers did not change significantly as a function of irradiation category or delivered dose. This is due in part to the difficulty in identifying outliers in groups of 5 to 15 dosimeter readings. For the discussions of energy dependence in the following sections all dosimeter results have been recalculated without outliers.

\subsection{X-RAY ENERGY DEPENDENCE}

$X$-ray tests in addition to the fields specified in draft ANSI N13.11 were included to evaluate the energy response of the dosimeters. X-ray irradiation categories ranged in effective energy from $16 \mathrm{keV}$ (K-fluorescent technique) to $167 \mathrm{keV}$ (HFI technique). Biases for reported shallow and deep doses are plotted in Figures 5 through 10 in order of ascending effective energy for both TL and film dosimeters. Explicit energy-dependence curves are not intended.

The shallow and deep dose performance of TL dosimeters are shown in Figures 5 through 8 . Only three categories were included for the tests using participant calibrations. After the recalibration, additional categories were tested. Biases for systems with fixed calibrations are indicated by closed circles and with variable calibrations by open circles. Dosimeters with fixed calibrations utilize a predetermined algorithm to determine shallow and deep dose, regardless of radiation type and energy. Variable-calibration dosimeters function as a crude spectrometer with ratios of element responses used as a basis for adjusting reported dose.

The variable-calibration TL dosimeters performed better than those with fixed calibrations. For the recalculated data (Figures 7 and 8 ), the calibration points for variable-calibration dosimeters are indicated by square 


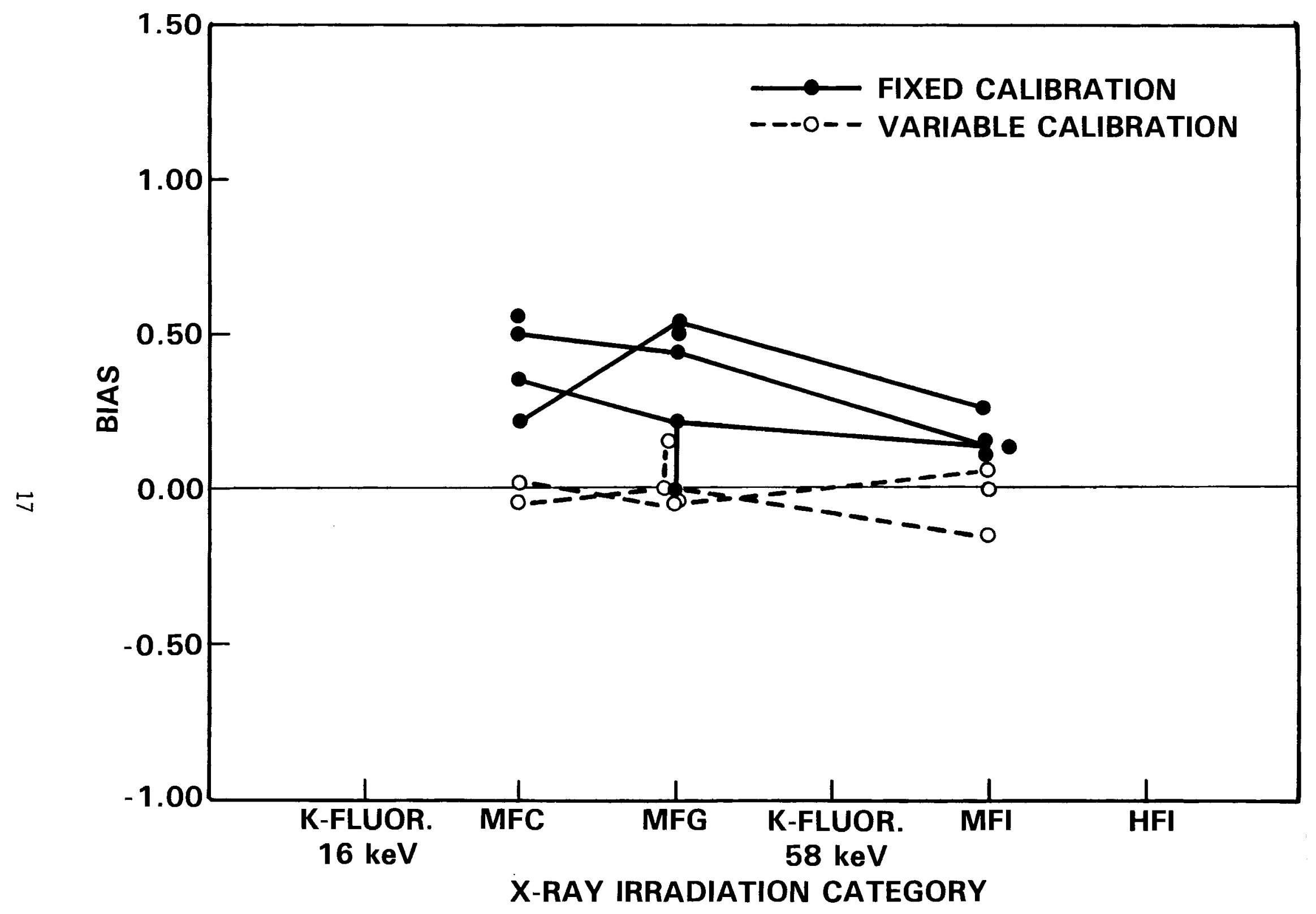

FIGURE 5. X-Ray Shallow Dose Performance of TLD Dosimeters (Participant Calibration) 


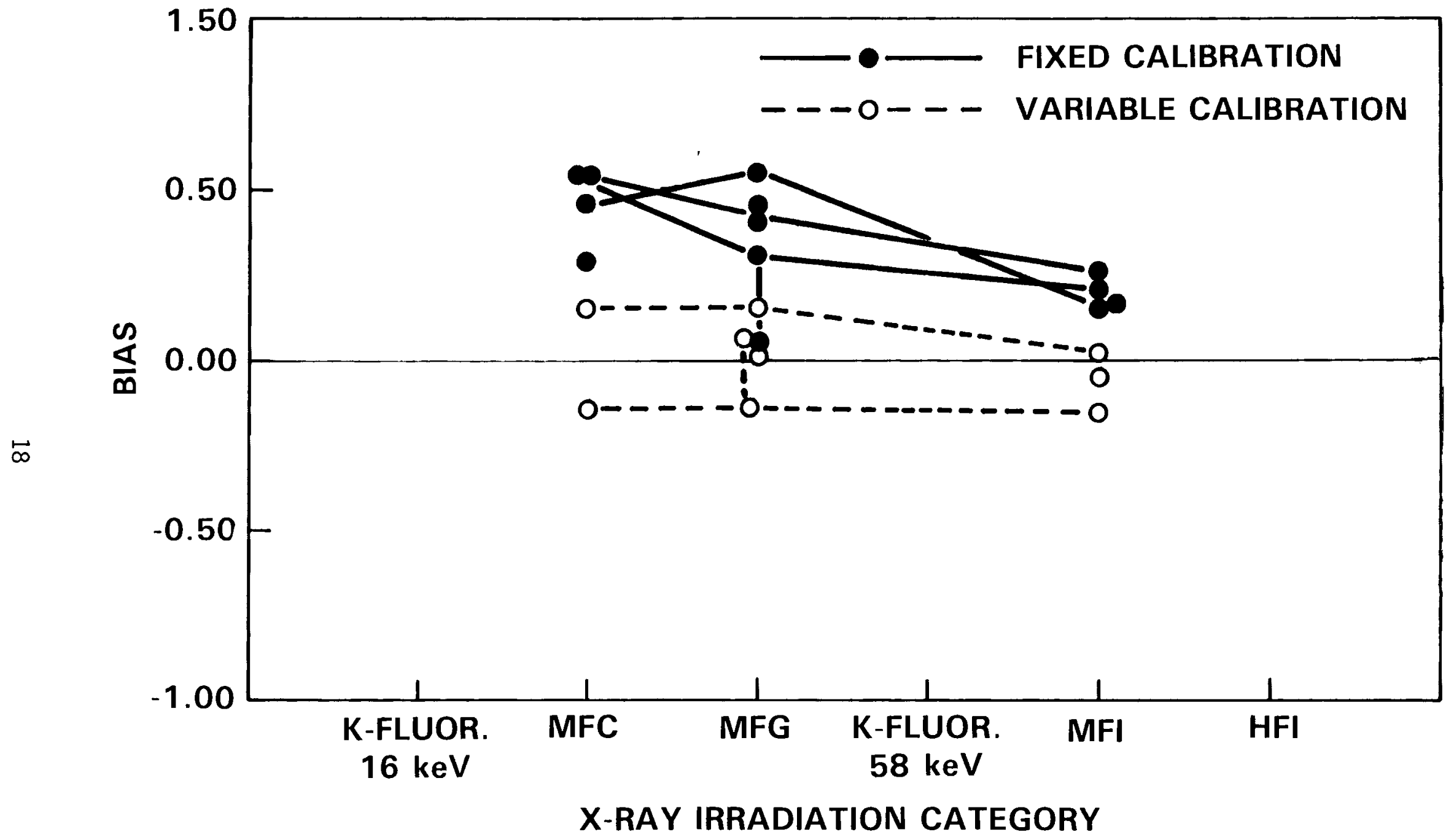

FIGURE 6. X-Ray Deep Dose Performance of TL Dosimeters (Participant Calibration) 


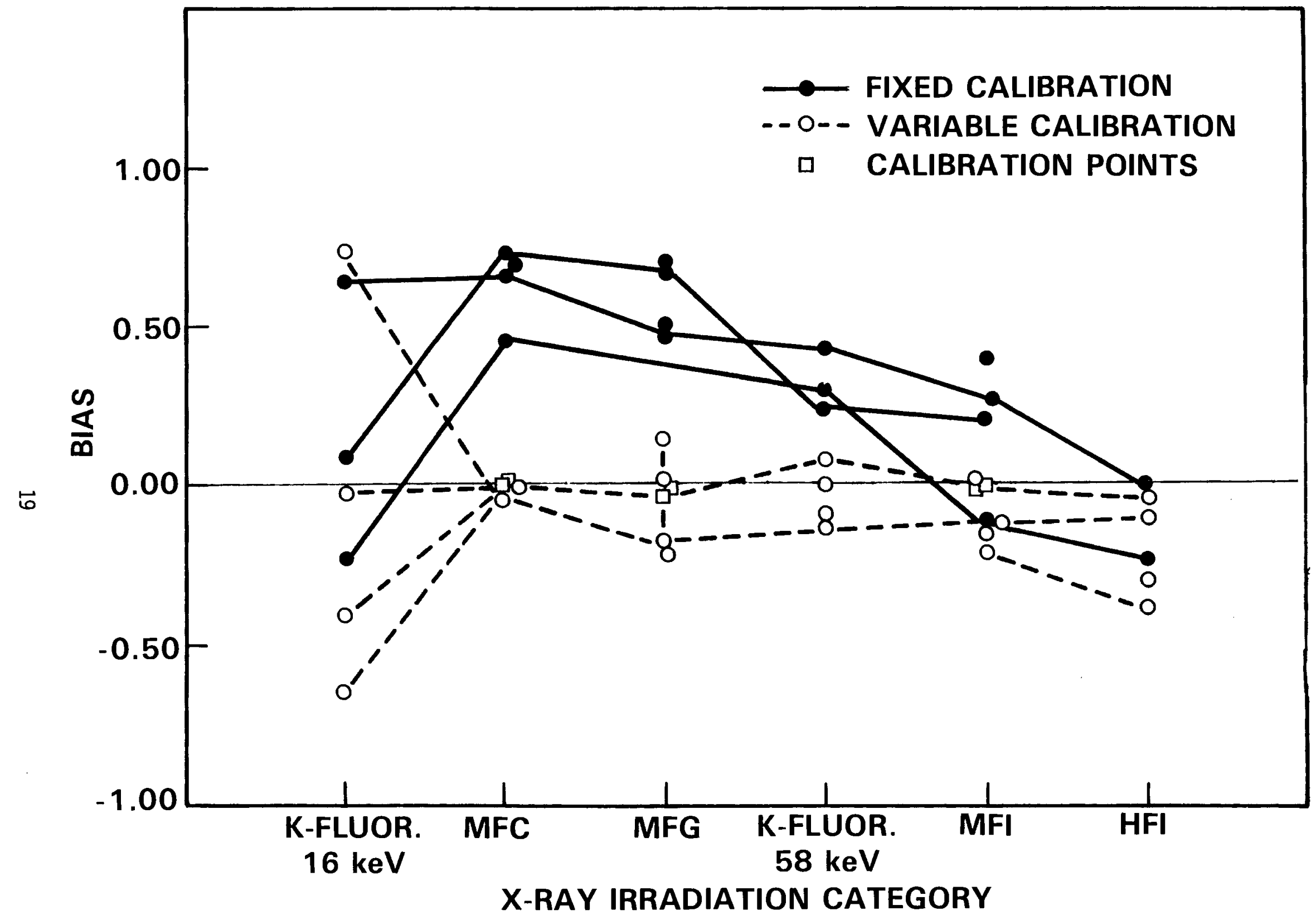

FIGURE 7. X-Ray Shallow Dose Performance of TL Dosimeters

(Recalibrated Based on PNL Irradiations) 


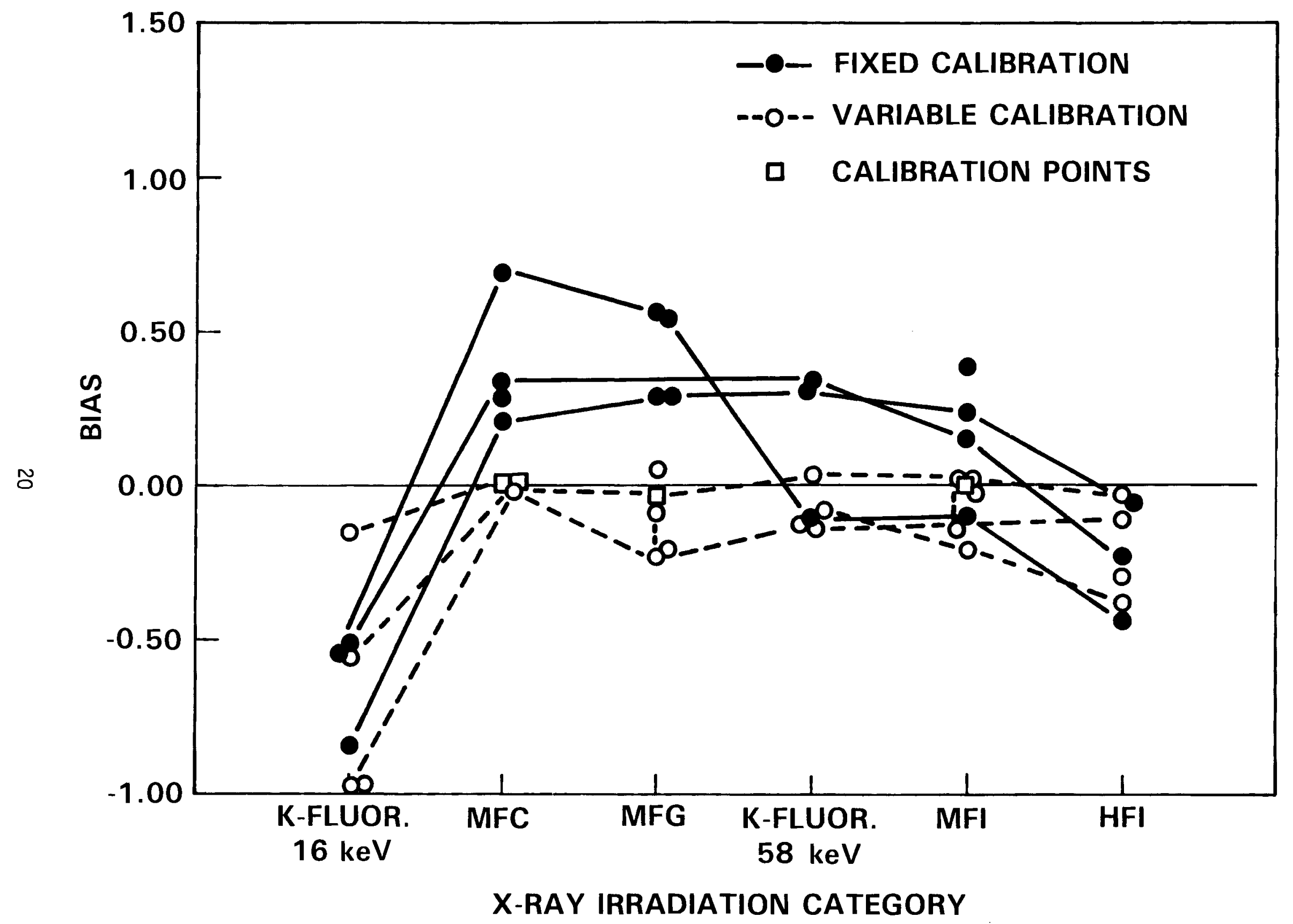

FIGURE 8. X-Ray Deep Dose Performance of TL Dosimeters

(Recalibrated Based on PNL Irradiations) 


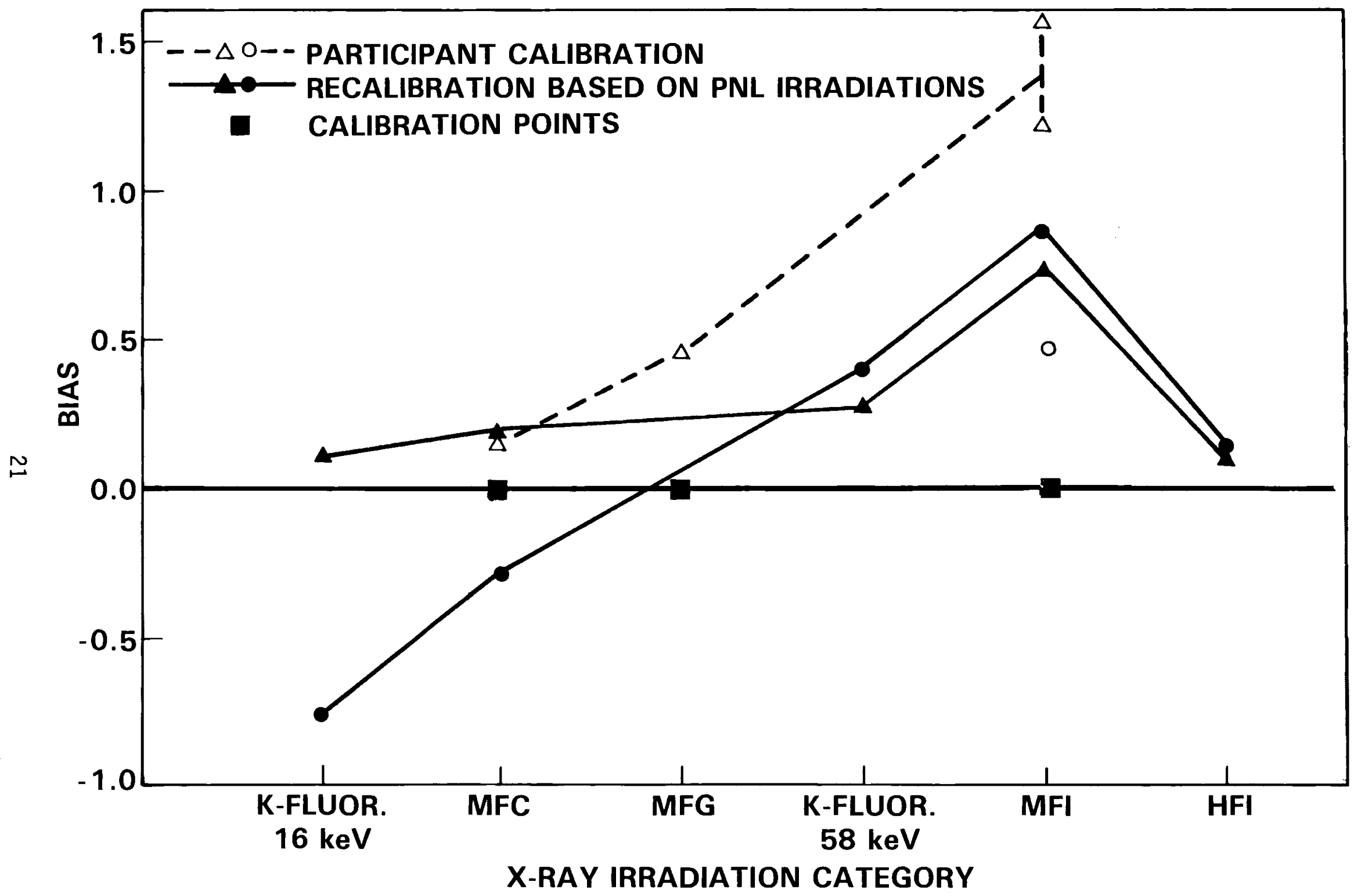

FIGURE 9. X-Ray Performance of Film Dosimeters (Shallow Dose) 


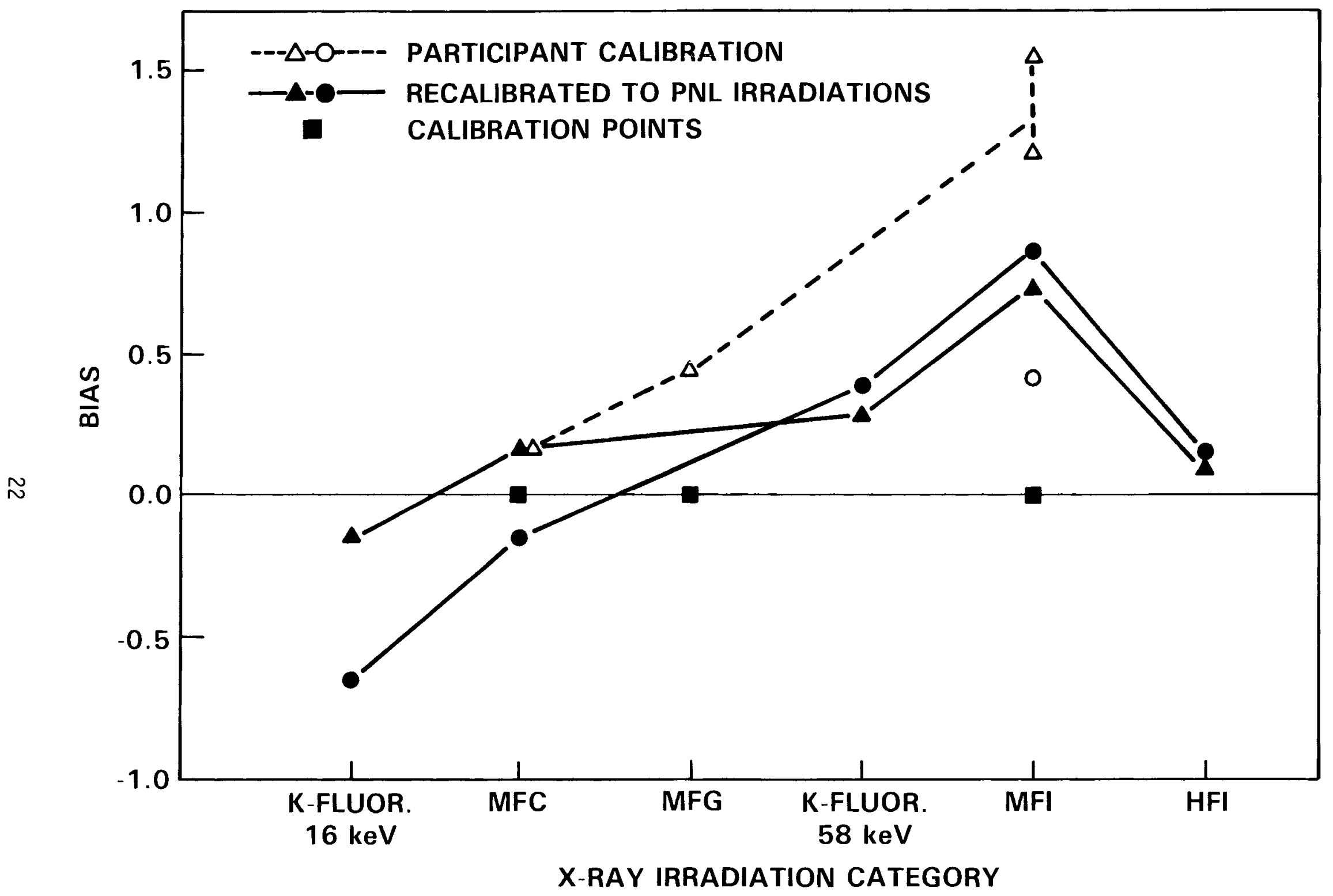

FIGURE 10. X-Ray Performance of Film Dosimeters (Deep Dose) 
symbols. Processors using a fixed calibration were not able to improve dosimeter performance even when provided with delivered doses at three calibration points, because the responses to $x$-ray, beta and ${ }^{137} \mathrm{Cs}$ calibrations are not independent. The recalibration of the $x$-ray categories causes a degradation of performance in the other categories. The performance for $16-k e V$ k-fluorescent $x$-ray irradiations was poor, varied widely, and was not related to dosimeter type. Dosimeter systems with both fixed and variable calibration TL dosimeters had difficulty interpreting the 16-keV shallow dose.

The energy response of film dosimeters is shown in Figures 9 and 10. Interpretation of doses from film is more difficult because the dosimeter interpretation must account for both energy dependence and dose dependence. The irradiations provided for recalibration were not as useful for the film dosimeter systems because only a narrow range of doses were provided at each energy. The $x$-ray performance of the film dosimeters was generally poorer than both the fixed-and variable-calibration TL dosimeters.

The performance of the variable-calibration TL dosimeters was superior to that for the other methods. The film dosimeters had the least desirable performance because of the difficulty associated with calibrating to broad-width spectra such as the NBS medium- and lightly filtered techniques. One laboratory declined participation in the $x$-ray category because of the effort required to calibrate their film system. Another laboratory could not reconcile PNL calibrations with other $x$-ray calibration beams, including those of the same NBS techniques.

\subsection{BETA ENERGY DEPENDENCE AND CALIBRATION EFFECTS}

The low-energy beta response for the participating dosimeters was determined using exposures to ${ }^{85} \mathrm{Kr}$ and ${ }^{90} \mathrm{Sr} /{ }^{90} \mathrm{Y}$ sources. The response per unit delivered dose of ${ }^{85} \mathrm{Kr}$ was divided by the response per unit dose of ${ }^{90} \mathrm{Sr} /{ }^{90} \mathrm{Y}$, and plotted as a function of filtration thickness (see Figure 11). Dosimeters using thick TL elements $\left(230 \mathrm{mg} / \mathrm{cm}^{2}\right)$ showed the lowest response, which decreased further with increasing filtration. One TL dosimeter type responded anomalously: almost zero signal with very little filtration over the shallowdose element. Other designs exposed to ${ }^{85} \mathrm{Kr}$ during the same irradiations responded normally. The best response, $70 \%$, was achieved with a sensitive $\mathrm{TL}$ 


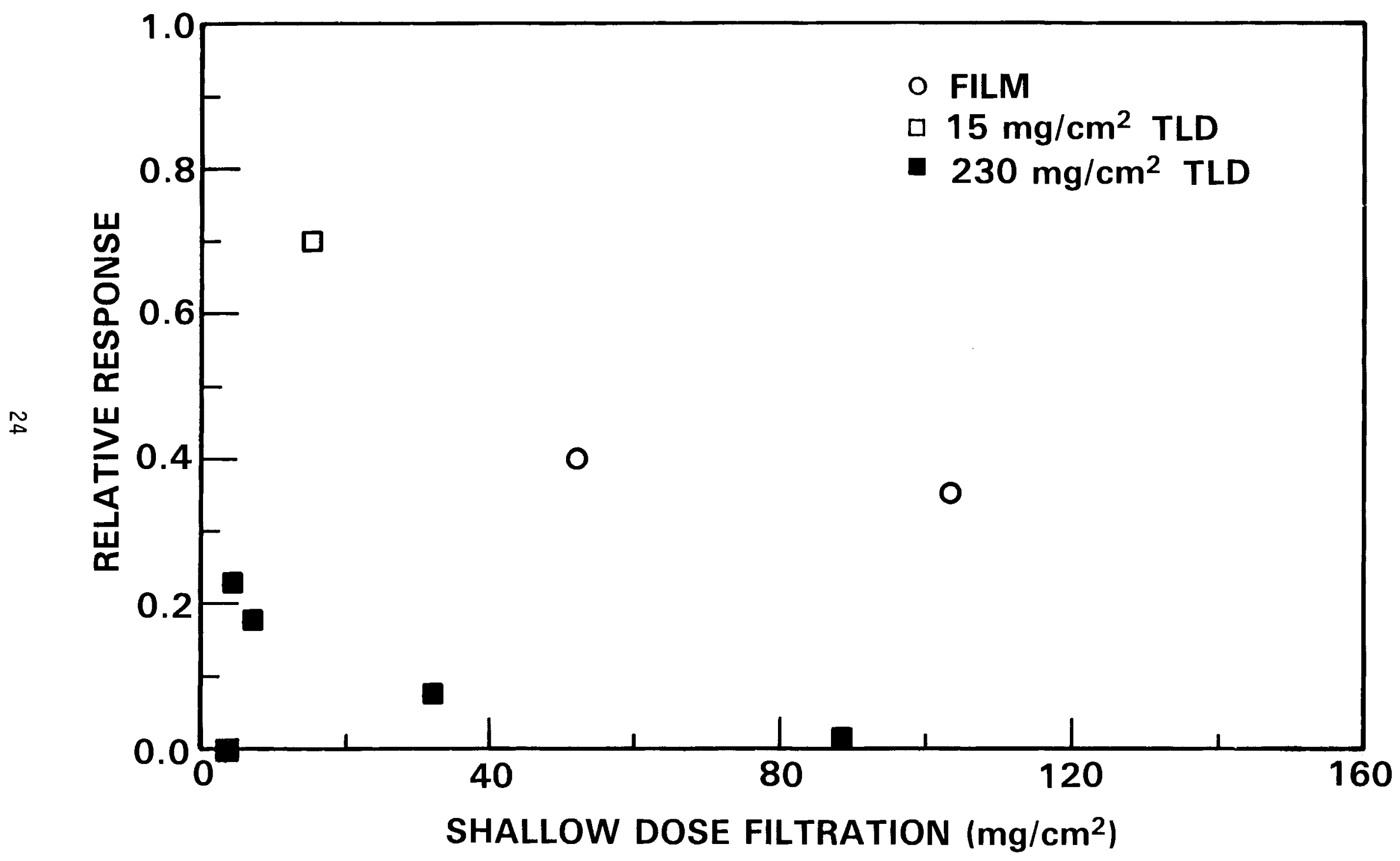

FIGURE 11. Low-Energy Beta Response $\left({ }^{85} \mathrm{Kr} /{ }^{90} \mathrm{Sr}-{ }^{90} \mathrm{Y}\right)$ 
element approximately $15 \mathrm{mg} / \mathrm{cm}^{2}$ in thickness. Film-dosimeter data is sparse. It appears that the low-energy beta response is poor, although superior to the response of dosimeters using thick $T L$ elements. The amount of filtration material used contributed to the poor response of both film and TL dosimeters.

Performance for the ${ }^{90} \mathrm{Sr} /{ }^{90} \mathrm{Y}$ category as a function of calibration technique is summarized in Figure 12. Participants calibrated to ${ }^{90} \mathrm{Sr} /{ }^{90} \mathrm{Y}$, uranium slab or photon dose normalized to $\mathrm{Sr}$, uranium slab surface dose, or photon shallow dose. Results varied widely. The normalized photon and uranium calibrations were acceptable for the dosimeters studied. A uranium slab surface dose calibration provided excellent results for the film dosimeters but unacceptable results for the thick TL dosimeters. This is probably due to the on-contact irradiation geometry and the contribution from low-energy betas enhancing the dose rate at $7 \mathrm{mg} / \mathrm{cm}^{2}$ compared to dose rate at the sensitive depths of the TL dosimeters (Plato 1979).

The film performance for the ${ }^{90} \mathrm{Sr} /{ }^{90} \mathrm{y}$ calibration is anomalous. Major differences in calibrations are expected due to differences in effective filtrations, but the bias of $40 \%$ is higher than expected.

\subsection{NEUTRON CAL IBRATION EFFECTS, ENERGY DEPENDENCE}

AND MIXED FIELD PERFORMANCE

Unmoderated ${ }^{252} \mathrm{Cf}$ irradiations, moderated ${ }^{252} \mathrm{Cf}$ irradiations and mixedfield irradiations of unmoderated ${ }^{252} \mathrm{Cf}$ with $k$-fluorescent $x$ rays were used to evaluate neutron dosimetry capabilities. A more detailed investigation of DOE neutron dosimetry performance may be found elsewhere (McDonald et al. 1983).

The unmoderated ${ }^{252} \mathrm{Cf}$ category showed a large variation in dosimeter response when based on participant calibrations. Part of this inconsistency can be attributed to neutron scatter in the participant calibration facilities. For $\mathrm{TL}$ albedo dosimeters calibrated to unmoderated ${ }^{252} \mathrm{Cf}$ a rough correlation between calibration facility size and dosimeter performance bias was observed. The effective room radius for each facility was calculated based on room dimensions. When the facility provided only one scatter surface (e.g., an outdoor calibration range or metal building with concrete floor) the effective room radius that would yield the same amount of scatter in an enclosed room was 


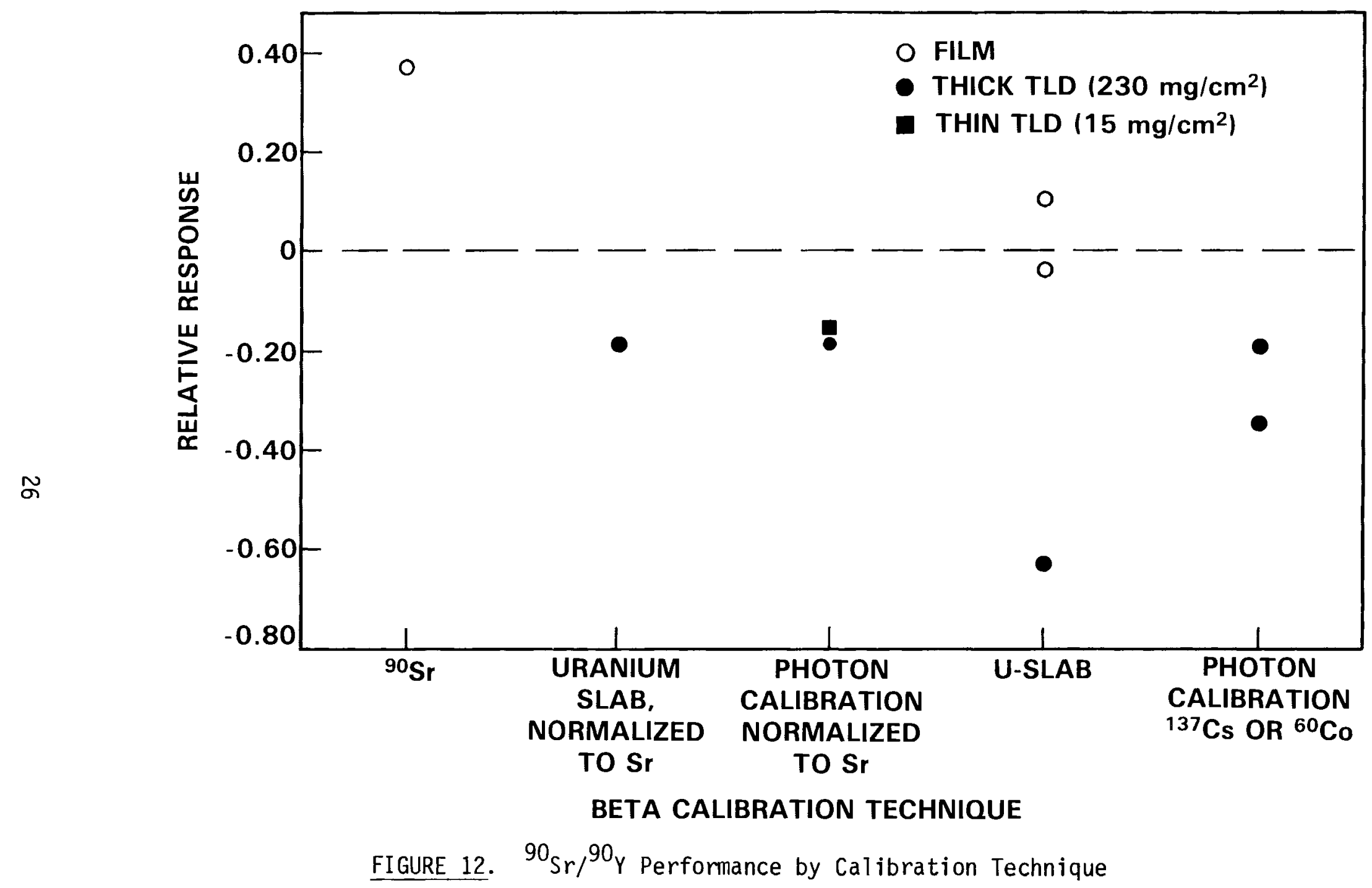


estimated. Since the relative scatter component increases with the source-tophantom detector distances, all room radi $i$ were normalized to an irradiation distance of $50 \mathrm{~cm}$. Thus for a dosimeter irradiated at $1 \mathrm{~m}$, the room radius was decreased by a factor of two. Formulas for room scatter are found in NBS Special Publication 633, "Procedures for Calibrating Neutron Personnel Dosimeters" (Schwartz and Eisenhauer 1982).

The dosimeter bias is plotted as a function of effective room radius in Figure 13 for five participants using TL albedo dosimeters calibrated to unmoderated ${ }^{252} \mathrm{Cf}$. One data point for a $\mathrm{TL}$ albedo dosimeter with a plutonium beryllium calibration is included for reference. Results were excluded from Figure 13 because the participants used a calibration referenced to the work environment, the scatter conditions were too complex to permit calculation of an effective room radius, or insufficient data existed to characterize the neutron response. For the participants studied, the bias approached zero for large calibration facilities (low scatter conditions). High scatter facilities resulted in low dosimeter response relative to the PNL calibration. The results are general, since the calculations of effective room radius provide only a rough estimation of actual calibration conditions. A simplified theoretical response (for TL albedo dosimeters irradiated at $50 \mathrm{~cm}$ ) as a function of effective calibration facility radius is shown by a dotted line.

To test dosimeter energy dependence, neutron dosimeters were exposed at NBS to a ${ }^{252} \mathrm{Cf}$ source moderated by $15 \mathrm{~cm}$ of $\mathrm{D}_{2} 0$. Participants were instructed to use the calibration to bare ${ }^{252} \mathrm{Cf}$ provided by PNL. Results varied widely. Biases ranged from 7 and 21 for the ten laboratories reporting moderated ${ }^{252} \mathrm{Cf}$ data. These are summarized in Table 3.

For purposes of comparison, TL-albedo dosimeters were categorized by design. The Hankins-type albedo dosimeters utilize neutron-sensitive and neutron-insensitive elements enclosed in $30 \mathrm{mil}$ cadmium. Dose equivalent calculations are based on the neutron-sensitive TLD reading, corrected for photon contribution and energy response. In the asymmetric design, the response of a neutron-sensitive TLD element shielded in front by cadmium is compared to the response of an element shielded in back by cadmium or unshielded by cadmium. In one dosimeter, boron is substituted for cadmium. 


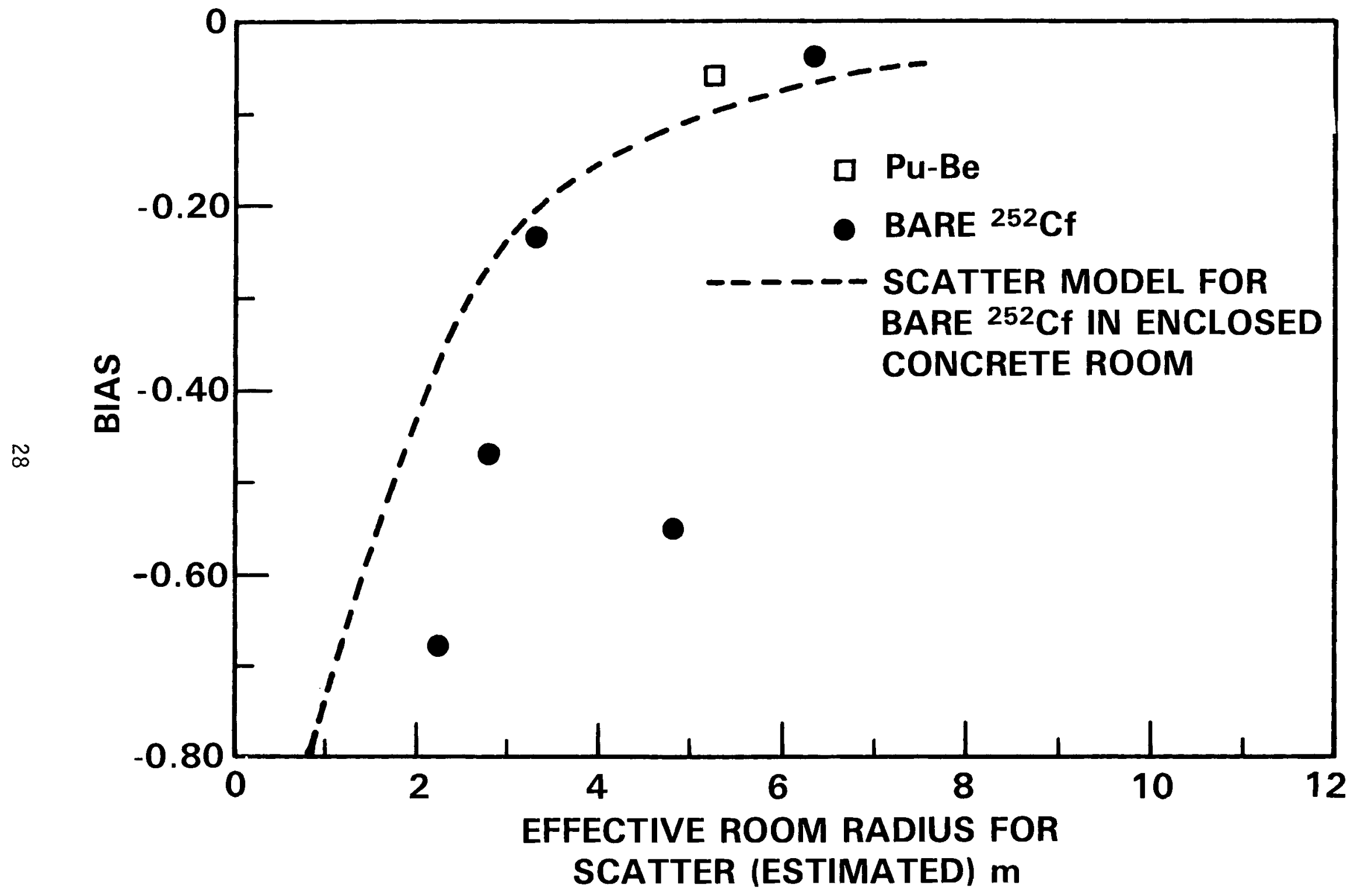

FIGURE 13. TLD-Albedo Dosimeter Performance as a Function of Calibration Facility Scatter 
TABLE 3. Dosimeter Response to Moderated ${ }^{252} \mathrm{Cf}$, Relative to Unmoderated ${ }^{252} \mathrm{Cf}$

\begin{tabular}{|c|c|c|c|}
\hline Processor & Dosimeter Type & Bias & Standard Devia \\
\hline A & TLD albedo ${ }^{(e)}$ & 6.9 & 1.7 \\
\hline B & TLD albedo ${ }^{(d)}$ & 7.6 & 0.7 \\
\hline c & TLD albedo & $0.74^{(a)}$ & 0.1 \\
\hline D & TLD albedo $(c)$ & 20 & 0.6 \\
\hline$E$ & TLD albedo $(c)$ & 21 & 0.5 \\
\hline $\mathrm{F}$ & NTA film & $-(b)$ & $-(1$ \\
\hline G & TLD albedo ${ }^{(d)}$ & 9.5 & 1.7 \\
\hline$H$ & TLD albedo ${ }^{(d)}$ & 8.9 & 0.6 \\
\hline I & TLD albedo $(c)$ & 12 & 0.5 \\
\hline $\mathrm{J}$ & TLD albedo $(c)$ & 21 & 1.0 \\
\hline$k$ & TLD albedo ${ }^{(d)}$ & 6.4 & 0.3 \\
\hline
\end{tabular}

(a) Did not use unmoderated ${ }^{252} \mathrm{Cf}$ calibration.

(b) No reported data (severe fading).

(c) Hankins-type dosimeter.

(d) Asymmetric design.

(e) Other.

Interpretation methods vary. For all designs, the dosimeters must be calibrated to spectra similar to the occupational environment. The energy dependence test provides an indication of dosimeter performance, when the calibration and field spectra differ significantly. Performance was determined by dosimeter design features, since participants were instructed to use the PNL unmoderated ${ }^{252} \mathrm{Cf}$ calibration to interpret dose.

Dosimeter energy dependence was variable and not clearly related to design. Three of the Hankins' type dosimeters showed a significantly higher response to moderated californium with biases of 20-21. A fourth Hankins design was less energy dependent with a bias of 12 . Biases for the asymmetric absorber designs ranged from 6.4 to 9.5. The participant with the lowest bias did not calibrate the dosimeter as specified in the test. Data for NTA emulsion was not available due to high fading and long holding periods for the testing. 
Dosimeter response to mixed neutron/x-ray fields was difficult to interpret. Dosimeters were exposed to randomized dose equivalents of ${ }^{252} \mathrm{Cf}$ ranging from 101 to 365 mrem in conjunction with $58 \mathrm{keV} k$-fluorescent $x$-ray exposures of 69 to $248 \mathrm{mR}$. Out of the eight facilities participating in the category, only two participants reported neutron doses. Both of these participants interpreted the neutron component correctly, with biases of $13 \%$ or less. The lack of reported data for neutrons may be attributable to participant expectation of a beta or gamma irradiation. This category may not have been a realistic test of dosimeter response to mixed neutron/x-ray fields encountered in the work environment, since the effective energy of unmoderated ${ }^{252} \mathrm{Cf}$ is higher than that of plutonium. However, the high rate of missed neutron dose implies a potential serious problem area.

\subsection{EVALUATION OF DOSIMETER PERFORMANCE BASED ON OTHER EXISTING STANDARDS}

In addition to the criteria in the draft versions of ANSI N13.11, guidance for dosimeter system performance is presented in ANSI N13.7, "American National Standard Criteria for Film Badge Performance," (ANSI 1972) and ANSI N319, "American National Standard for Personnel Neutron Dosimeters (Neutron Energies less than $20 \mathrm{MeV}$ )" (ANSI 1976). Where applicable, dosimeter performance was evaluated based on criteria presented in these documents.

The criteria for film dosimeter performance (ANSI N13.7) differ from the ANSI N13.11 criteria with respect to irradiation conditions, reporting units for photon irradiations, test procedures, and statistical evaluation procedures. Although the ANSI N13.7 criteria cannot be applied directly, the film dosimeter performance can be predicted based on the observed test results.

The film dosimeter performance criteria defines an additive component and multiplicative component to dosimeter bias. Calculation of each component requires dosimeter irradiations at several uniform exposure levels. Since exposure levels were randomized for the performance testing, the statistical evaluation procedures outlined in ANSI N13.7 are not applicable. However, the bias components may be estimated using a linear regression on the reported and delivered doses. An equation of the form 


$$
D_{i} \simeq a+b E_{i}
$$

is assumed, where $D_{i}$ is the reported dose, $E_{i}$ is the delivered dose, 'a' is the estimated additive component of dosimeter bias and ' $b$ ' is the estimated multiplicative component of dosimeters bias. Values of ' $a$ ' and ' $b$ ' were estimated for the three participants using film dosimetry for beta-gamma measurements. All x-ray irradiations correspond to NBS technique MFI. Values of 'a' and ' $b$ ' for photon categories were calculated from shallow and deep dose, rather than the units of exposure specified in ANSI N13.7. Neutron results for the NTA film were seriously affected by fading and are not included. The calculated values of $a$ and $b$ for each irradiation category are listed in Tables 4 and 5, using data for February through April, participant calibrations. The uncertainty for each value of 'a' listed in the table is large.

TABLE 4. Estimated Additive Bias For Film Dosimeters (ANSI N13.7 Criteria)

\begin{tabular}{|c|c|c|c|}
\hline \multirow[b]{2}{*}{ Irradiation Category } & \multicolumn{3}{|c|}{ Estimated Values of ' $a$ ' (mrem) } \\
\hline & Participant D & Participant $F$ & Participant $\mathrm{j}$ \\
\hline${ }^{137}$ Cs deep dose & 16 & -8 & 5 \\
\hline$X$ ray shallow dose (MFI) & 91 & (a) & 35 \\
\hline$X$ ray deep dose (MFI) & 18 & (a) & 36 \\
\hline${ }^{90}{ }_{S r /}{ }^{90} Y$ & -6 & -31 & 35 \\
\hline
\end{tabular}

(a) Did not participate.

TABLE 5. Estimated Multiplicative Bias For Film Dosimeters (ANSI N13.7 Criteria)

\begin{tabular}{|c|c|c|c|}
\hline \multirow[b]{2}{*}{ Irradiation Category } & \multicolumn{3}{|c|}{ Estimated Values of ' $b$ ' } \\
\hline & Participant D & Participant F & Participant \\
\hline${ }^{137}$ Cs deep dose & 1.10 & 1.05 & 0.92 \\
\hline$X$ ray shallow dose (MFI) & 2.35 & (a) & 1.33 \\
\hline$X$ ray deep dose (MFI) & 2.53 & (a) & 1.38 \\
\hline${ }^{90} \mathrm{Sr} /{ }^{90} \mathrm{Y}$ & 1.41 & 1.00 & 0.85 \\
\hline
\end{tabular}

(a) Did not participate. 
The criteria for film performance specifies allowable conditions for 'a' and 'b.' For any level of exposure $E_{i},\left(E_{i}>40 \mathrm{mrem}\right)$ used in the testing, the following condition should be met:

$$
\left|\frac{E_{i}(b-1)+a}{E_{i}-a}\right|<0.10
$$

If the bias criteria is not achieved, the participant must apply the bias corrections ' $a$ ' and ' $b$ ' to future test results. This is not a pass-fail criteria. The bias criteria serves as an indication that the system must be adjusted to monitor specific energies. The values of the bias criteria for film processors are shown in Table 6. The results suggest that bias corrections are needed for all categories shown with the exception of ${ }^{90} \mathrm{Sr}$ doses above a few hundred mrem for processor $F$, and ${ }^{137} C_{S}$ for processors $F$ and $J$.

TABLE 6. Bias Criteria for Film Dosimeters

\begin{tabular}{|c|c|c|c|c|}
\hline $\begin{array}{c}\text { Irradiation } \\
\text { Category }\end{array}$ & $\begin{array}{l}\text { Dose } \\
\text { Level } \\
\text { (mrem) } \\
\end{array}$ & \multicolumn{3}{|c|}{ Values of $\left|\frac{E_{j}(b-1)+a}{E_{i}-a}\right|$} \\
\hline${ }^{137} \mathrm{CS}$ & $\begin{array}{r}100 \\
500 \\
1000\end{array}$ & $\begin{array}{l}0.30 \\
0.13 \\
0.11\end{array}$ & $\begin{array}{l}0.03 \\
0.03 \\
0.04\end{array}$ & $\begin{array}{l}0.03 \\
0.07 \\
0.08\end{array}$ \\
\hline$x$ ray shallow dose & $\begin{array}{r}100 \\
500 \\
1000\end{array}$ & $\begin{array}{r}>25 \\
1.87 \\
1.58\end{array}$ & - & $\begin{array}{l}1.04 \\
0.43 \\
0.38\end{array}$ \\
\hline$X$ ray deep dose & $\begin{array}{r}100 \\
500 \\
1000\end{array}$ & $\begin{array}{l}2.09 \\
1.62 \\
1.57\end{array}$ & - & $\begin{array}{l}1.15 \\
0.49 \\
0.43\end{array}$ \\
\hline${ }^{90} \mathrm{Sr} /{ }^{90_{Y}}$ & $\begin{array}{r}100 \\
500 \\
1000\end{array}$ & $\begin{array}{l}0.33 \\
0.39 \\
0.40\end{array}$ & $\begin{array}{l}0.44 \\
0.07 \\
0.03\end{array}$ & $\begin{array}{l}0.30 \\
0.09 \\
0.12\end{array}$ \\
\hline
\end{tabular}


The criteria for neutron dosimeter performance presented in ANSI N319 (ANSI 1976) specifies, in part, that the neutron dosimetry system sha11 be capable of detecting a minimum quarteriy dose of $300 \mathrm{mrem}$, or a monthly dose of 100 mrem (if monthly reporting is used). The lower limit of detection defined by the standard is the dose equivalent at which the observed standard deviation in reported dose for a group of ten dosimeters is $50 \%$. The dosimeter system must be capable of detecting a neutron dose equivalent of one rem when irradiated in conjunction with a three-rem dose of photons with energies above $500 \mathrm{keV}$. In addition, the observed standard deviation of reported dose for a group of ten or more dosimeters irradiated under identical conditions to approximately one rem neutron dose equivalent must be $10 \%$ or less.

The fifteen dosimeters irradiated in the performance comparison were exposed to random levels of dose equivalent over a three month period. Although the criteria for neutron dosimeter variability cannot be fairly applied to the dosimeter results, it seems unlikely that a variability of $10 \%$ is achievable for all participants. Some participants may experience difficulty with the requirements for monitoring mixed photon-neutron fields, as indicated by the sparse reporting of neutron dose in the mixed $x$-ray/neutron category (Section 4.6). 


\subsection{CONCLUSIONS AND RECOMMENDATIONS}

Dosimeter system performance was influenced by dosimeter design, calibration methodology, dose interpretation technique, and dosimeter handling technique. The performance comparison provided a means of evaluating dosimeter performance in terms of existing standards, as well as identifying parameters that aided or hindered dose interpretation. Dosimeter performance according to the ANSI N13.11 criteria is summarized in Section 5.1 and Appendix A. Conclusions are included in Section 5.2 and desirable design features identified during the performance comparison are surmarized in Section 5.3.

\subsection{EVALUATION OF DOSIMETER PERFORMANCE USING ANSI N13.11 PERFORMANCE CRITERIA}

The dosimeter results presented in Sections 4.1 to 4.2 are summarized in a pass/fail format in Table 7. A passing performance is indicated if the sum of the dosimeter bias and standard deviation is less than or equal to 0.5 . A marginally passing performance is indicated if the sum of the bias and standard deviation is between 0.35 and 0.5. Failure in a category is indicated by a score greater than 0.5. Dosimeter results are presented for Phase I (participant calibrations), Phase II (PNL calibrations), and Phase II with outliers deleted.

Oniy two participants passed all categories before recalibration to PNL irradiations. Two participants not participating in a 11 categories had passing scores for all data submitted. Before recalibration, one participant passed nine of the ten tests, two participants passed eight of ten tests, two participants passed seven of ten tests and three participants passed six of ten tests.

The greatest benefit from recalibration to PNL irradiations was observed in the neutron category. Out of six faitures in the category, four were upgraded to a passing score after recalibration. One participant passed after an extreme dosimeter reading was omitted. The remaining failure corresponded to a laboratory that did not participate in the recalibration. The beta category benefitted slightly, with one of two failures changed to a passing score. 
TABLE 7. Dosimeter Performance Using ANSI N13.11 Performance Criteria

\begin{tabular}{|c|c|c|c|c|c|c|c|c|c|c|c|c|c|}
\hline Participant & $\begin{array}{l}\text { Data } \\
\text { Set }\end{array}$ & $\begin{array}{l}\text { Photon } \\
\text { Shallow }\end{array}$ & $\frac{\left.{ }^{37} \mathrm{Cs}\right)}{\text { Deep }}$ & $\frac{X \mathrm{Ra}}{\text { Shallow }}$ & Deep & $\frac{\text { Beta }}{\text { Shallow }}$ & $\frac{{ }^{137} \mathrm{Cs} / \mathrm{x}}{\text { Sha!low }}$ & $\frac{\text { Ray }}{\text { Deep }}$ & $\begin{array}{l}\text { Photon } \\
\text { Shallow }\end{array}$ & $\frac{\text { Beta }}{\text { Deep }}$ & $\frac{\text { Neutron }}{\text { Fast }}$ & $\frac{\text { Total }}{\text { Passed }}$ & $\frac{\text { Tests }}{\text { Failed }}$ \\
\hline$A$ & $\begin{array}{l}1 \\
2 \\
3\end{array}$ & $\begin{array}{l}P \\
P \\
P\end{array}$ & $\begin{array}{l}P \\
P \\
P\end{array}$ & $\begin{array}{l}P \\
P \\
P\end{array}$ & $\begin{array}{l}P \\
P \\
P\end{array}$ & $\begin{array}{l}P \\
P \\
P\end{array}$ & $\begin{array}{l}P \\
P \\
P\end{array}$ & $\begin{array}{l}P \\
P- \\
P-\end{array}$ & $\begin{array}{l}P \\
F \\
F\end{array}$ & $\begin{array}{l}P \\
P- \\
P-\end{array}$ & $\begin{array}{l}P \\
p \\
P \star\end{array}$ & $\begin{array}{r}10 \\
9 \\
9\end{array}$ & $\begin{array}{l}0 \\
1 \\
1\end{array}$ \\
\hline$B$ & $\begin{array}{l}1 \\
2 \\
3\end{array}$ & $\begin{array}{l}\text { P- } \\
\text { P- } \\
\text { P- }\end{array}$ & $\begin{array}{l}P- \\
P- \\
P-\end{array}$ & $\begin{array}{l}P \\
P \\
P *\end{array}$ & $\begin{array}{l}P \\
P \\
P\end{array}$ & $\begin{array}{l}F \\
F \\
F\end{array}$ & $\begin{array}{l}P \\
P \\
P\end{array}$ & $\begin{array}{l}P \\
P- \\
P-\end{array}$ & $\begin{array}{l}F \\
F \\
F^{*}\end{array}$ & $\begin{array}{l}F \\
P- \\
P-\end{array}$ & $\begin{array}{l}F \\
P \\
P *\end{array}$ & $\begin{array}{l}6 \\
8 \\
8\end{array}$ & $\begin{array}{l}4 \\
2 \\
2\end{array}$ \\
\hline D & $\begin{array}{l}1 \\
2 \\
3\end{array}$ & $\begin{array}{l}P \\
P \\
P\end{array}$ & $\begin{array}{l}P \\
P \\
P\end{array}$ & $\begin{array}{l}F \\
F \\
F^{*}\end{array}$ & $\begin{array}{l}F \\
F \\
F^{*}\end{array}$ & $\begin{array}{l}F \\
P \\
P\end{array}$ & $\begin{array}{l}F \\
F \\
F\end{array}$ & $\begin{array}{l}P- \\
P \\
P\end{array}$ & $\begin{array}{l}P \\
P \\
P\end{array}$ & $\begin{array}{l}P \\
P \\
P\end{array}$ & $\begin{array}{l}P \\
P \\
P\end{array}$ & $\begin{array}{l}6 \\
7 \\
7\end{array}$ & $\begin{array}{l}4 \\
3 \\
3\end{array}$ \\
\hline $\mathrm{E}$ & $\begin{array}{l}1 \\
2 \\
3\end{array}$ & $\begin{array}{l}P \\
P \\
P^{*}\end{array}$ & $\begin{array}{l}P \\
P \\
P\end{array}$ & $\begin{array}{l}F \\
F \\
F^{*}\end{array}$ & $\begin{array}{l}P \\
P \\
P\end{array}$ & $\begin{array}{l}P \\
P \\
P *\end{array}$ & $\begin{array}{l}P- \\
P- \\
P-\end{array}$ & $\begin{array}{l}P \\
P \\
P\end{array}$ & $\begin{array}{l}P \\
P \\
P\end{array}$ & $\begin{array}{l}P \\
P \\
P *\end{array}$ & $\begin{array}{l}F \\
P \\
P *\end{array}$ & $\begin{array}{l}8 \\
9 \\
9\end{array}$ & $\begin{array}{l}2 \\
1 \\
1\end{array}$ \\
\hline G & $\begin{array}{l}1 \\
2 \\
3\end{array}$ & $\begin{array}{l}P \\
P \\
P\end{array}$ & $\begin{array}{l}\mathrm{P} \\
\mathrm{P} \\
\mathrm{P}\end{array}$ & $\begin{array}{l}P \\
P \\
P\end{array}$ & $\begin{array}{l}P \\
P \\
P\end{array}$ & $\begin{array}{l}P- \\
P \\
P *\end{array}$ & $\begin{array}{l}P \\
P \\
P\end{array}$ & $\begin{array}{l}P \\
P \\
P\end{array}$ & $\begin{array}{l}\text { P- } \\
\text { P- } \\
\text { P- }\end{array}$ & $\begin{array}{l}P \\
P \\
P\end{array}$ & $\begin{array}{l}F \\
P \\
P\end{array}$ & $\begin{array}{r}9 \\
10 \\
10\end{array}$ & $\begin{array}{l}1 \\
0 \\
0\end{array}$ \\
\hline $\mathrm{H}$ & $\begin{array}{l}1 \\
2 \\
3\end{array}$ & $\begin{array}{l}P \\
P \\
P\end{array}$ & $\begin{array}{l}P \\
P \\
P\end{array}$ & $\begin{array}{l}P \\
P \\
P\end{array}$ & $\begin{array}{l}P \\
P \\
P\end{array}$ & - & $\begin{array}{l}P \\
P \\
P\end{array}$ & $\begin{array}{l}P \\
P \\
P\end{array}$ & - & - & $\begin{array}{l}P \\
P \\
P\end{array}$ & $\begin{array}{l}7 \\
7 \\
7\end{array}$ & $\begin{array}{l}0 \\
0 \\
0\end{array}$ \\
\hline 1 & $\begin{array}{l}1 \\
2 \\
3\end{array}$ & $\begin{array}{l}P \\
P \\
P\end{array}$ & $\begin{array}{l}P \\
P \\
P\end{array}$ & $\begin{array}{l}P \\
P \\
P\end{array}$ & $\begin{array}{l}P \\
P \\
P\end{array}$ & $\begin{array}{l}P \\
P \\
P\end{array}$ & $\begin{array}{l}\text { P- } \\
\text { P- } \\
P-\end{array}$ & $\begin{array}{l}\text { P- } \\
\text { P- } \\
\text { P- }\end{array}$ & $\begin{array}{l}P \\
P \\
P\end{array}$ & $\begin{array}{l}P \\
P \\
P\end{array}$ & $\begin{array}{l}\text { P- } \\
\text { P- } \\
\text { P- }\end{array}$ & $\begin{array}{l}10 \\
10 \\
10\end{array}$ & $\begin{array}{l}0 \\
0 \\
0\end{array}$ \\
\hline $\mathrm{J}$ & $\begin{array}{l}1 \\
2 \\
3\end{array}$ & $\begin{array}{l}P \\
P \\
P\end{array}$ & $\begin{array}{l}P \\
P \\
P\end{array}$ & $\begin{array}{l}P- \\
F \\
F\end{array}$ & $\begin{array}{l}F \\
F \\
F\end{array}$ & $\begin{array}{l}P \\
P \\
P^{*}\end{array}$ & $\begin{array}{l}P \\
P \\
P\end{array}$ & $\begin{array}{l}P- \\
P \\
P\end{array}$ & $\begin{array}{l}P \\
P \\
P\end{array}$ & $\begin{array}{l}P \\
P \\
P\end{array}$ & $\begin{array}{l}F \\
P \\
P\end{array}$ & $\begin{array}{l}8 \\
8 \\
8\end{array}$ & $\begin{array}{l}2 \\
2 \\
2\end{array}$ \\
\hline$k$ & $\begin{array}{l}1 \\
2 \\
3\end{array}$ & $\begin{array}{l}P \\
P \\
P *\end{array}$ & $\begin{array}{l}P \\
P \\
P\end{array}$ & $\begin{array}{l}F \\
F \\
F^{\star}\end{array}$ & $\begin{array}{l}F \\
F \\
F^{\star}\end{array}$ & $\begin{array}{l}P \\
P \\
P\end{array}$ & $\begin{array}{l}P \\
P \\
P\end{array}$ & $\begin{array}{l}P \\
P \\
P\end{array}$ & $\begin{array}{l}P \\
P \\
P\end{array}$ & $\begin{array}{l}\text { P } \\
\text { P- } \\
\text { P- }\end{array}$ & $\begin{array}{l}F \\
F \\
P \star\end{array}$ & $\begin{array}{l}7 \\
7 \\
8\end{array}$ & $\begin{array}{l}3 \\
3 \\
2\end{array}$ \\
\hline
\end{tabular}

1 = Participant calibrations.

$2=$ PNL calibrations.

$3=$ PNL calibrations, $*=$ outlier deleted.

$P=$ Pass; $B+S<0.5$.

$\mathrm{P}_{-}=$Marginal pass; $0.35<\mathrm{B}+\mathrm{S}<0.50$.

$F=F a i l$. 
Dosimeter performance was not corrected by recalibration in the $x$-ray category (four failures before recalibration, an additional failure after recalibration), the ${ }^{137} \mathrm{Cs} / x$-ray category (one failure) and the mixed photon/ beta shallow dose category (two failures before recalibration, an additional failure after recalibration). The difficulty in recalibrating to $x$ rays and beta/photon mixtures was due to the dose interpretation techniques. Shallow doses from betas and photons were not determined independently in several of the dosimeter designs; any change in the calibration for one category had an adverse effect on the other category.

When recalibrated data was re-evaluated excluding outliers, only one failing score improved sufficiently to pass, although overall dosimeter performance improved (see Section 4.3).

\subsection{CONCLUSIONS}

Most participants in the intercomparison experienced difficulties in passing the irradiation categories specified in ANSI N13.11. The only category in which all participants performed well was ${ }^{137} \mathrm{Cs}$. Poor performance in the remaining five categories can be traced to individual dosimetry system features such as calibration technique, physical design, dosimeter screening and handling techniques, and dose interpretation techniques.

The most significant calibration effects were observed in the beta and neutron categories. Most participating dosimetry systems were extremely energy dependent, resulting in large discrepancies in dosimeter response under varying calibration conditions. Beta calibration techniques varied widely; dosimeter response was much more uniform after recalibration to the PNL source. While special work conditions could require different calibrations, in general the variability of calibrations was too great. Many neutron calibrations appeared to be approximately correlated with the level of scattered neutrons present in the calibrating facility.

Deficiencies in dosimeter design and dose calculation technique were the major cause of poor performance in the low-energy photon category. In most cases the photon energy dependence of dosimeters was not adequately addressed. Interpretation of photon dose was particularly difficult for film dosimetry 
systems. Some TLD systems also performed poorly. The best performance in the $x$-ray categories was achieved with TL dosimeters utilizing a response correction for phosphor energy dependence (variable calibration dosimeters). When no response-correction was used (fixed calibration dosimeters), successful recalibration to PNL $x$-ray irradiations was not achievable.

Poor dosimeter performance for the low-energy beta irradiations was attributed to dosimeter design. A clear relationship between dosimeter element thickness, shallow-dose element filtration, and beta energy dependence was observed.

\subsection{RECOMMENDATIONS}

Improved standardization of beta and neutron calibration techniques is needed. The use of adjusted photon or uranium slab calibrations to simulate dosimeter response to ${ }^{90} \mathrm{Sr} /{ }^{90} \mathrm{Y}$ is subject to considerable error, and should be evaluated carefully. Even when a ${ }^{90} \mathrm{Sr} /{ }^{90} \mathrm{Y}$ source is used, differences in inherent source filtration and calibration geometry can be significant. For neutron calibrations, the use of scatter corrections for source-, air-, and room-scattered neutrons is recommended. The correction procedures are contained in "Procedures for Calibrating Neutron Personnel Dosimeters" (Schwartz and Eisenhauer 1982).

Approximately half of the participating dosimetry systems had inadequate performance for $x$-ray categories. We recommend the use of variable-calibration $T L$ dosimeters where low-energy $x$-ray dosimetry is required. However, care must be taken to set up the algorithm because the energy-correction formula can be misdirected to produce spurious results. We recommend that film dosimeters be phased out for x-ray dosimetry. Film-dosimeter performance was significantly more difficult to control than TL-dosimeter performance, making the probability of a miscalibrated dosimetry system much greater.

Dosimeter variability in the neutron categories was seriously affected by outliers. Where this is a problem, tight screening of neutron dosimeter elements or implementation of individual dosimeter sensitivity factors is recommended. Some of the participants with small quantities of dosimeters 
were able to use special TLD annealing procedures and glow curve analyses. Although this resulted in extremely low variability, it is recognized that such practices are not feasible for large dosimetry processors.

Only two of eight participating laboratories reported the neutron component of the $x$-ray/neutron mixture. This is a potentially serious problem. We recommend that facilities handling significant quantities of plutonium perform periodic checks of their ability to detect neutrons along with a comparable $x$-ray dose. 


\section{REFERENCES}

American National Standards Institute (ANSI). 1972. American National Standard, Criteria for Film Badge Performance. ANSI N13.7-1972. New York, New York.

American National Standards Institute (ANSI). 1976. American National Standard for Personnel Neutron Dosimeters (Neutron Energies Less than $20 \mathrm{MeV}$ ). ANSI N319-1976. New York, New York

American National Standards Institute (ANSI). 1978. Draft American National Standard, Criteria for Testing Personnel Dosimetry Performance. ANSI N13.11. New York, New York.

American National Standards Institute (ANSI). 1983. American National Standard, Criteria for Testing Personnel Dosimetry Performance. ANSI N13.111983. New York, New York.

McDonald, J. C., et al. 1983. Response Characteristics of Selected Personnel Neutron Dosimeters. PNL-3982, Pacific Northwest Laboratory, Richland, Washington.

Plato, P. 1979. "Absorbed Dose Rate Produced by Natural Uranium as a Function of Depth in Tissue." Int. J. App. Rad. Iso. 30:109-113.

Schwartz, R. B., and C. M. Eisenhauer. 1980. The Design and Construction of a $\mathrm{D}_{2} \mathrm{O}$-Moderated ${ }^{252} \mathrm{Cf}$ Source for Calibrating Neutron Personnel Dosimeters Used at Nuclear Power Reactors. NUREG/CR-1204, U.S. Nuclear Regulatory Commission, Washington, D.C.

Schwartz, R. B., and C. M. Eisenhauer. 1982. Procedures for Calibrating Neutron Personnel Dosimeters. NBS Special Publication 633, U.S. Department of Commerce, National Bureau of Standards, Washington, D.C.

Roberson, P. L., et al. 1983. Facilities and Procedures Used for Performance Testing of DOE Personnel Dosimetry Systems, PNL-4207. Pacific Northwest Laboratory, Richland, Washington.

U.S. National Bureau of Standards (NBS). 1981. Calibration and Related Measurement Services of the National Bureau of Standards. NBS Special Publication 250 and Appendix. U.S. Government Printing Office, Washington D.C. 


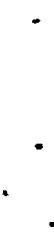


APPENDIX A

COMPILATION OF DOSIMETER PERFORMANCE DATA 


\section{COMPILATION OF DOSIMETER PERFORMANCE DATA}

The dosimeter performance data is tabulated in the form specified by ANSI N13.11 (ANSI 1983). The parameters B(bias), S (standard deviation), and PC (performance criterion) are defined below:

$$
\begin{aligned}
B & =\frac{1}{n} \sum_{i=1}^{n} P_{i} \\
S & =\left[\frac{1}{n-1} \sum_{i=1}^{n}\left(P_{i}-B\right)^{2}\right]^{1 / 2} \\
P_{i} & =\frac{\text { Reported (i) - Delivered (i) }}{\text { Delivered (i) }}
\end{aligned}
$$

and

$$
|B|+S=P C
$$

where $P_{i}$ is the performance quotient for the $i^{\text {th }}$ dosimeter, $n=15$ for Phase I and II and $n=5$ for Phase III. The performance algorithm given in ANSI N13.11 is

$$
|B|+S \leq L
$$

where the tolerance level $(L)$ is 0.5 for the radiation protection categories.

Results for Categories III through VIII of ANSI N13.11 (1978 draft, ANSI 1978) are given in Table A.1 for Phase I (based on participant calibration) and Phase II (based on PNL calibration). Categories I and II are for accident dosimetry and were not used for the performance testing. The eleven participating DOE laboratories were each randomly assigned a letter designation.

Tables A.2, A.3, and A.4 contain the results for the May, June, and July irradiation sets, respectively.

A listing of the test irradiations performed is given in Table 1 ( $p .4)$. 
TABLE A.1. Performance Data (Phases I and II)

TABLE A.1a. Category III: Low-Energy Photons (X Ray)

Participant Technique

Shallow

A

$c^{(d)}$

D

$\mathrm{E}$

$F^{(c)}$

G

H

I

$\mathrm{J}$

K

Deep

\begin{tabular}{lcc} 
A & MFG & $-0.00^{(a)}$ \\
$B$ & $M F G$ & 0.05 \\
C & MFC & 0.17 \\
$D$ & MFI & 1.57 \\
E & MFC & $0.28^{(a)}$ \\
F (c) & & \\
G & MFG & $0.07^{(b)}$ \\
H & MFI & $-0.05^{(b)}$ \\
I & MFI & 0.15 \\
J & MFI & 0.46 \\
K & MFG & 0.47 \\
\multicolumn{3}{l}{} \\
Inconsistency between sets. \\
Outtier. \\
Did not participate. \\
Data set of five dosimeters.
\end{tabular}

Phase I

$\mathrm{B}-\frac{\mathrm{S}}{\mathrm{PC}}$

$B$

Phase II

$\mathrm{S}-\mathrm{PC}$

$\begin{array}{llllclc}\text { MFG } & -0.04^{(a)} & 0.15 & 0.19 & -0.21^{(a)} & 0.11 & 0.31 \\ \text { MFG } & 0.01 & 0.10 & 0.11 & -0.18^{(b)} & 0.09 & 0.27 \\ \text { MFC } & 1.37 & 1.42 & 2.79 & -(c) & - & - \\ \text { MFI } & 1.98^{(a, b)} & 1.69 & 3.67 & 0.73^{(b)} & 0.20 & 0.93 \\ \text { MFC } & 0.56^{(a, b)} & 0.12 & 0.68 & 0.69^{(b)} & 0.13 & 0.81\end{array}$

$M F G$

$0.14^{(a)} \quad 0.07$

0.21

$0.14^{(a)}$

0.07

0.22

MF I

0.06

0.14

$-0.00$

0.04 .

0.04

MF I

0.11

0.09

0.20

0.11

0.09

0.20

MF I

0.07

0.48

0.86

0.09

0.96

MFG

0.11

0.64

$0.76^{(b)}$

0.17

0.94
0.16

0.10

0.02

0.45

0.11

0.08

0.06

0.10

0.07

0.13 $0.17-0.17^{(a)}$

0.16

0.18

2.02

0.39

0.15

0.11

0.25

0.53

0.60

$-0.24$

(c)

$0.73^{(b)}$
0.21

(b)

0.10

0.27

0.08

0.32

0.20

0.93

0.07

0.28 
TABLE A.1b. Category IV: High-Energy Photons $\left({ }^{137} \mathrm{Cs}\right)$

\begin{tabular}{|c|c|c|c|c|c|c|}
\hline \multirow[b]{2}{*}{ Participant } & \multicolumn{3}{|c|}{ Phase I } & \multicolumn{3}{|c|}{ Phase II } \\
\hline & B & S & $P C$ & B & $\mathrm{s}$ & $P C$ \\
\hline \multicolumn{7}{|l|}{ Deep } \\
\hline A & -0.16 & 0.13 & 0.28 & -0.20 & 0.09 & 0.28 \\
\hline B & -0.28 & 0.10 & 0.38 & -0.30 & 0.11 & 0.40 \\
\hline$c^{(a)}$ & 0.00 & 0.08 & 0.08 & (b) & & \\
\hline D & 0.16 & 0.05 & 0.21 & 0.14 & 0.05 & 0.18 \\
\hline$E$ & 0.02 & 0.05 & 0.07 & -0.04 & 0.07 & 0.11 \\
\hline $\mathrm{F}$ & 0.00 & 0.08 & 0.08 & 0.00 & 0.08 & 0.08 \\
\hline G & -0.17 & 0.06 & 0.23 & -0.17 & 0.06 & 0.23 \\
\hline$H$ & 0.03 & 0.06 & 0.09 & 0.04 & 0.07 & 0.11 \\
\hline I & -0.05 & 0.05 & 0.09 & -0.05 & 0.05 & 0.09 \\
\hline $\mathrm{J}$ & -0.05 & 0.05 & 0.10 & 0.00 & 0.05 & 0.05 \\
\hline$k$ & 0.05 & 0.08 & 0.13 & 0.11 & 0.08 & 0.19 \\
\hline
\end{tabular}

(a) Data set of five dosimeters.

(b) Did not participate. 
TABLE A.IC. Category V: Beta Particles $\left({ }^{90} \mathrm{Sr} /{ }^{90} \mathrm{Y}\right)$

Participant

Shallow

$A$
$C^{(d)}$
$D$
$E$
$F$
$G$
$H^{(C)}$
$I$
$J$
$K$

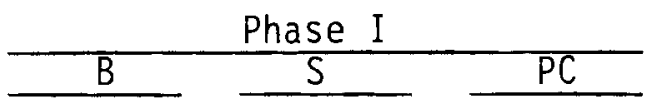

$$
-0.17
$$

0.08

$-0.63$

0.09

0.24

0.15

0.09

0.06

0.10

$-0.37$

$-0.22$

$0.02(a, b)$

0.08

0.23

$-0.19$

0.11
0.25

0.72

1.07

0.52

0.27

0.15

0.47

0.30

0.25

0.31

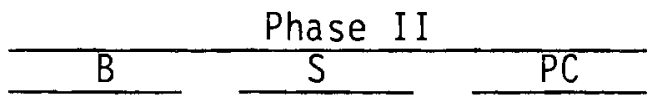

$-0.04$

0.09

0.12

$-0.43$

0.15

0.58

(c)

0.18

0.13

0.31

0.17

0.08

0.25

0.25

0.09

0.34

$-0.02$

0.22

0.24

$\begin{array}{lll}0.09^{(b)} & 0.12 & 0.21 \\ 0.15 & 0.10 & 0.26 \\ 0.04 & 0.15 & 0.19\end{array}$

(a) Inconsistency between sets.

(b) Outlier.

(c) Did not participate.

(d) Data set of five dosimeters. 
TABLE A.1d. Category VI: Photon Mixtures $\left({ }^{137} \mathrm{CS}+X\right.$ Ray $)$

$\underline{\text { Participant }}$ Technique $\frac{\text { Phase I }}{\mathrm{B}-\frac{\mathrm{S}}{\mathrm{PC}}}$

$\frac{\text { Phase II }}{\mathrm{S}-\mathrm{SC}}$

Shallow

\begin{tabular}{|c|c|c|c|c|c|c|c|}
\hline A & MF I & $-0.22^{(a)}$ & 0.10 & 0.33 & -0.27 & 0.11 & 0.38 \\
\hline B & MFI & -0.21 & 0.09 & 0.30 & -0.23 & 0.09 & 0.32 \\
\hline$c^{(d)}$ & MFG & 0.24 & 0.09 & 0.34 & (c) & & \\
\hline$D$ & MFC & 0.64 & 0.35 & 0.99 & 0.44 & 0.37 & 0.82 \\
\hline $\begin{array}{l}E \\
F(c)\end{array}$ & MFG & 0.26 & 0.12 & 0.38 & 0.23 & 0.14 & 0.36 \\
\hline$G$ & MFI & -0.11 & 0.12 & 0.23 & -0.07 & 0.09 & 0.16 \\
\hline $\mathrm{H}$ & MFC & -0.06 & 0.04 & 0.10 & 0.02 & 0.06 & 0.08 \\
\hline I & MFC & $0.25^{(a, b)}$ & 0.19 & 0.44 & $0.25^{(a, b)}$ & 0.19 & 0.44 \\
\hline $\mathrm{J}$ & MFC & 0.10 & 0.11 & 0.21 & 0.11 & 0.10 & 0.21 \\
\hline 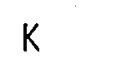 & MFI & $0.17^{(b)}$ & 0.11 & 0.28 & 0.32 & 0.17 & 0.49 \\
\hline
\end{tabular}

Deep

\begin{tabular}{|c|c|c|c|c|c|c|c|}
\hline A & MFI & $-0.26^{(a)}$ & 0.11 & 0.37 & $-0.27^{(a)}$ & 0.11 & 0.37 \\
\hline B & MFI & -0.22 & 0.09 & 0.31 & -0.25 & 0.10 & 0.35 \\
\hline$c^{(d)}$ & MFG & 0.14 & 0.07 & 0.21 & (c) & & \\
\hline D & MFC & 0.31 & 0.12 & 0.43 & 0.11 & 0.18 & 0.29 \\
\hline $\begin{array}{l}E \\
F(c)\end{array}$ & MFG & $0.19^{(a)}$ & 0.12 & 0.31 & 0.12 & 0.07 & 0.19 \\
\hline G & MF I & $-0.10^{(a, b)}$ & 0.10 & 0.20 & -0.11 & 0.10 & 0.21 \\
\hline H & MFC & -0.02 & 0.04 & 0.05 & 0.01 & 0.06 & 0.07 \\
\hline I & MFC & $0.29(a, b)$ & 0.17 & 0.46 & $0.29^{(a, b)}$ & 0.17 & 0.46 \\
\hline J & MFC & 0.21 & 0.14 & 0.35 & -0.07 & 0.08 & 0.15 \\
\hline 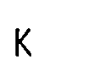 & MF I & $0.11^{(a)}$ & 0.11 & 0.22 & 0.18 & 0.12 & 0.30 \\
\hline
\end{tabular}

(a) Inconsistency between sets.

(b) Outlier.

(c) Did not participate.

(d) Data set of five dosimeters. 
TABLE A.le. Category VII: Photon/Beta-Particle Mixtures $\left({ }^{137} \mathrm{Cs}+{ }^{90} \mathrm{Sr} / 90 \mathrm{Y}\right)$

Participant

Shallow

A

${ }^{\text {B }}(d)$

D

E

$\mathrm{F}$

G

$H^{(c)}$

I

J

K

Deep

$\begin{array}{lcc}\text { A } & -0.26^{(a)} & 0.11 \\ B & 0.14 & 0.37 \\ \text { C (d) } & 0.08 & 0.08 \\ \text { D } & 0.12^{(b)} & 0.31 \\ \text { E } & -0.02^{(a)} & 0.10 \\ F & 0.03 & 0.08 \\ G & -0.08 & 0.12 \\ \text { H (c) } & & \\ \text { I } & 0.00 & 0.11 \\ \text { J } & -0.04 & 0.08 \\ \text { K } & 0.13^{(a)} & 0.20 \\ & \\ \text { Inconsistency between sets. } \\ \text { Outlier. } \\ \text { Did not participate. } \\ \text { Data set of five dosimeters. }\end{array}$

(a) Inconsistency between sets.

(b) Outiier.

(c) Did not participate.

(d) Data set of five dosimeters.
Phase I

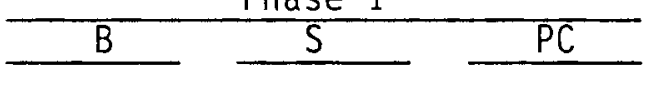

$-0.17^{(a)}$

0.13

0.12

0.30

0.59

0.14

0.10

0.12

0.10

0.09

0.11

0.11

0.13

0.55

0.33

0.20

0.15

0.44

0.24

0.18

0.26

0.37

0.51

0.17

0.43

0.12

0.11

0.20

0.11

0.12

0.33

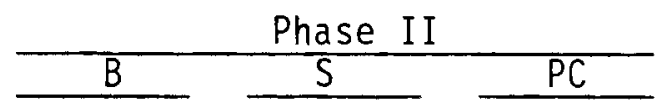

$-0.46$

$-0.55^{(b)}$

0.22

0.68

(c)

0.15

0.07

0.17

0.13

0.58

$-0.35$

$-0.10$

0.08

0.18

0.05

0.11

0.16

$0.06^{(b)}$

0.14

0.20

$0.05 \quad 0.20$

0.13

0.20

0.25

0.44

0.09

$-0.25^{(a)}$

0.11

0.37

$-0.14$

0.21

0.35

(c)

$$
0.18
$$

$-0.04^{(b)}$

0.04

0.22

0.03

0.07

0.11

$-0.08$

0.08

0.11

0.12

0.20

$-0.07$

0.14

0.21

0.01

0.09

0.11

0.20

0.21

0.41 
TABLE A.1f. Category VIII: Neutrons $\left({ }^{252} \mathrm{Cf}\right)$

Participant

Phase I

$\underline{\text { Fast }}$

$\begin{array}{llllccc}A & -0.26^{(a, b)} & 0.16 & 0.42 & -0.08(a, b) & 0.20 & 0.28 \\ B & -0.68^{(b)} & 0.10 & 0.78 & -0.23(b) & 0.25 & 0.48 \\ C^{(c, e)} & -0.70 & 0.06 & 0.76 & - & - & - \\ D & -0.06 & 0.10 & 0.16 & -0.01 & 0.14 & 0.15 \\ \text { E } & -0.27^{(b)} & 0.32 & 0.59 & 0.05 & 0.44 & 0.50 \\ F^{(c)} & -0.27 & 0.13 & 0.40 & - & - & - \\ G & -0.55^{(a)} & 0.09 & 0.64 & -0.02 & 0.19 & 0.20 \\ H & -0.04 & 0.16 & 0.20 & -0.02 & 0.12 & 0.14 \\ \text { I } & -0.20 & 0.17 & 0.37 & -0.07 & 0.20 & 0.27 \\ J & -0.47 & 0.07 & 0.54 & 0.09 & 0.14 & 0.22 \\ \text { K } & -0.59(a) & 0.23 & 0.83 & -0.15(a) & 0.44 & 0.58\end{array}$

Total

$\begin{array}{llllllc}A & -0.29(\mathrm{a}, \mathrm{b}) & 0.14 & 0.43 & -0.12^{(a, b)} & 0.18 & 0.30 \\ B & -0.68^{(a)} & 0.10 & 0.77 & -0.26^{(b)} & 0.24 & 0.50 \\ C^{(d)} & - & - & - & - & - & - \\ D^{(d)} & - & - & - & - & - & - \\ E & & & & & - & - \\ F(c) & -0.26 & 0.13 & 0.39 & - & 0.18 & 0.23 \\ G & -0.54(a) & 0.09 & 0.63 & -0.05 & 0.11 & 0.15 \\ H & -0.06 & 0.15 & 0.20 & -0.04 & 0.23 & 0.35 \\ I & -0.23 & 0.20 & 0.44 & -0.12 & 0.12 \\ J & -0.47 & 0.07 & 0.54 & 0.06 & 0.13 & 0.19 \\ K & -0.59 & 0.20 & 0.79 & -0.18(a) & 0.38 & 0.56\end{array}$

Phase I

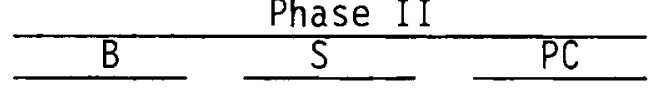

\footnotetext{
(a) Inconsitency between sets.

(b) Outlier.

(c) Unable to recalculate dosimeter response based on PNL calibration.

(d) Deep dose not report.

(e) Data set of ten dosimeters.
} 
TABLE A.2. Peformance Data (Phase III, May)

\section{Participant}

Shallow

A

B

$c^{(b)}$

D

E

$\mathrm{F}$

$G(c)$

$\mathrm{H}$

$I^{(c)}$

$j(c)$

K

Deep

A

B

$c^{(b)}$

D

E

$\mathrm{F}$

$G(c)$

H

I (c)

j(c)

$\mathrm{K}$
$X$-Ray, MFG

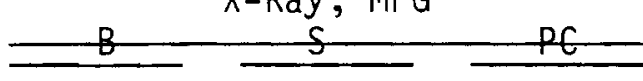

0.02

0.08

0.09

0.13

0.02

$-$

0.00

0.02

0.06

0.08

0.00

0.03

0.03

0.06

0.02

0.16

0.08

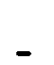

0.08

0.19
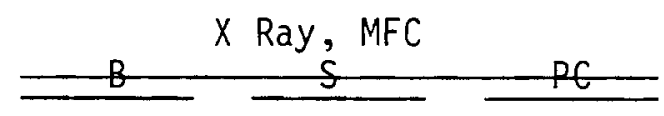

$-0.01$

0.01

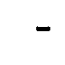

0.00

0.68

-(b)

$-$

0.00

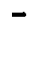

0.73

0.09

0.13

0.02

$-0.11$

0.08

$-0.03$

0.03

0.06

$-0.00$

0.05

0.05

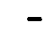

0.00

0.02

0.02

0.09

0.08

0.00

0.08

0.03

0.03

0.06

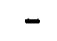

$-$

0.06

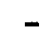

0.03

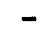

0.00

0.28

- (b)

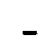

0.01

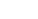

$-$

0.68
0.03

0.04

0.03

0.02

0.76

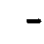

$-$

0.05

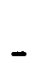

1.08

(a) Outlier.

(b) Did not participate.

(c) Not reported. 
TABLE A.2. (continued)

Participant

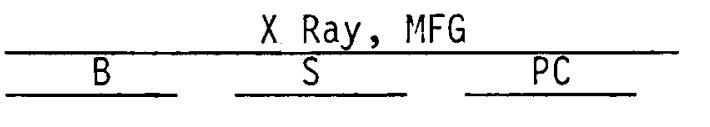

$\frac{X \text { Ray, MFI }}{\mathrm{S}}-\mathrm{PC}$

Shallow

$\begin{array}{lcccccc}\text { A } & -0.02 & 0.11 & 0.13 & -0.01 & 0.02 & 0.03 \\ \text { B } & -0.03 & 0.05 & 0.08 & 0.05 & 0.02 & 0.06 \\ \text { C(b) } & - & - & - & - & - & -\end{array}$

$\begin{array}{lcccccc}D & -0.01 & 0.01 & 0.02 & -0.01 & 0.03 & 0.03 \\ E & 0.50 & 0.18 & 0.68 & 0.27 & 0.09 & 0.36 \\ F & -(b) & - & - & -(b) & - & - \\ G(c) & - & - & - & - & - & - \\ H & -0.03 & 0.04 & 0.07 & 0.00 & 0.03 & 0.03 \\ \text { I(c) } & - & - & - & - & - & - \\ \text { J(c) } & - & - & - & - & - & - \\ K & 0.68 & 0.13 & 0.81 & 0.40 & 0.16 & 0.56\end{array}$

Deep

$\begin{array}{lcccccc}A & -0.03 & 0.11 & 0.14 & -0.04 & 0.04 & 0.08 \\ B & -0.08 & 0.04 & 0.12 & 0.02 & 0.04 & 0.06 \\ C^{(b)} & - & - & - & - & - & - \\ D & -0.01 & 0.01 & 0.02 & -0.01 & 0.02 & 0.03 \\ E & 0.30 & 0.08 & 0.38 & 0.24 & 0.11 & 0.34 \\ F & -(b) & - & - & -(b) & - & - \\ G(c) & - & - & - & - & - & - \\ H & -0.04 & 0.04 & 0.07 & -0.00 & 0.03 & 0.03 \\ { }_{I}(c) & - & - & - & - & - & - \\ J(c) & - & - & - & - & - & - \\ K & 0.54 & 0.09 & 0.64 & 0.38 & 0.08 & 0.46\end{array}$
(a) Outlier.
(b) Did not participate.
(c) Not reported. 
TABLE A.2. (continued)

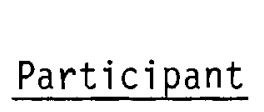

Shallow

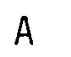

$B$

$c^{(b)}$

D

E

$\mathrm{F}$

$G(c)$

$\mathrm{H}$

I (c)

$j(c)$

K

A

B

$c^{(b)}$

D

E

$\mathrm{F}$

$G^{(c)}$

H

I (c)

$j(c)$

K

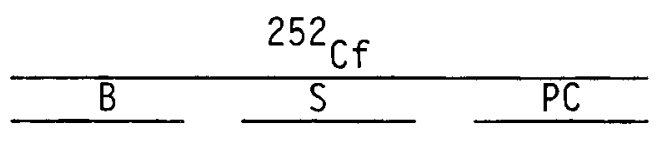

Fast

0.03

0.17

0.20

$-0.03$

0.12

0.16

0.07

0.34

0.24

0.01

0.11

0.12

0.17

0.04

0.21

0.05

0.10

0.16

0.19

0.03

0.22

0.00

0.17

0.17

(b)

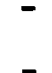

0.00

0.07

0.07

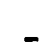

0.16

0.00

0.16

0.16

$\frac{\text { Total }}{0.03}$

0.15

0.18

$-0.05$

0.12

0.17

$-$

(d)

0.02

0.18

0.20

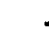

$-0.03$

0.06

0.09

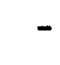

$-0.04$

0.14

0.18

\footnotetext{
(a) Outlier.

(b) Did not participate.

(c) Not reported.

(d) Deep dose not reported.
} 
TABLE A.3. Performance Data (Phase III, June)

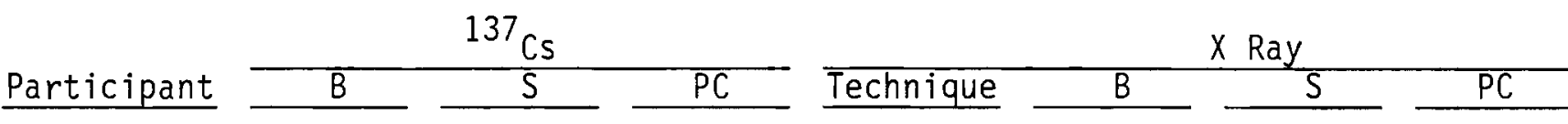

Shàllow

$\begin{array}{lccccccc}\text { A } & -0.07 & 0.07 & 0.14 & \text { MFI } & 0.02 & 0.08 & 0.10 \\ \text { B } & -0.27 & 0.03 & 0.30 & \text { MFI } & -0.14 & 0.03 & 0.17 \\ \text { C (b) } & - & - & - & \text { MFG } & - & - & - \\ \text { D } & -0.08 & 0.02 & 0.09 & \text { MFC } & 0.16 & 0.06 & 0.22 \\ \text { E } & 0.03 & 0.05 & 0.08 & \text { MFG } & 0.46 & 0.18 & 0.64 \\ \text { F } & -0.05 & 0.02 & 0.08 & & - \text { (b) } & - & - \\ \text { G } & -0.27 & 0.06 & 0.33 & \text { MFI } & -0.22 & 0.06 & 0.27 \\ \text { H } & -0.08 & 0.02 & 0.10 & \text { MFC } & -0.00 & 0.09 & 0.10 \\ \text { I } & -0.04 & 0.09 & 0.13 & \text { MFC } & 0.45 & 0.13 & 0.58 \\ \text { J } & -0.06 & 0.03 & 0.09 & \text { MFC } & -0.15 & 0.07 & 0.22 \\ \text { K } & -0.04 & 0.09 & 0.13 & \text { MFI } & 0.20 & 0.10 & 0.30\end{array}$

Deep

$\begin{array}{lccccccc}\text { A } & -0.07 & 0.07 & 0.14 & \text { MFI } & -0.04 & 0.07 & 0.10 \\ \text { B } & -0.28 & 0.04 & 0.32 & \text { MFI } & -0.14 & 0.05 & 0.19 \\ \text { C(b) } & - & - & - & \text { MFG } & - & - & - \\ \text { D } & -0.08 & 0.02 & 0.09 & \text { MFC } & 0.20 & 0.06 & 0.26 \\ \text { E } & -0.01 & 0.07 & 0.08 & \text { MFG } & 0.30 & 0.06 & 0.36 \\ \text { F } & -0.05 & 0.02 & 0.08 & & - \text { (b) } & - & - \\ \text { G } & -0.29 & 0.03 & 0.32 & \text { MFI } & -0.21 & 0.07 & 0.28 \\ \text { H } & -0.08 & 0.02 & 0.10 & \text { MFC } & -0.01 & 0.08 & 0.09 \\ \text { I } & -0.13 & 0.06 & 0.19 & \text { MFC } & 0.33 & 0.10 & 0.43 \\ \text { J } & -0.06 & 0.03 & 0.09 & \text { MFC } & -0.28 & 0.06 & 0.34 \\ \text { K } & -0.32 & 0.11 & 0.43 & \text { MFI } & -0.11 & 0.10 & 0.21\end{array}$

(a) Outlier.

(b) Did not participate. 
TABLE A.3. (continued)

252

\begin{tabular}{|c|c|c|c|c|c|c|}
\hline \multirow[b]{2}{*}{ Participant } & \multirow{2}{*}{$\frac{58-\mathrm{keV}}{\mathrm{B}}$} & \multicolumn{2}{|c|}{-ffurorescent X Ray } & \multicolumn{3}{|c|}{${ }^{252} \mathrm{Cf}$} \\
\hline & & $S$ & $P C$ & $B$ & 5 & $P C$ \\
\hline & Deep & & & Fast & & \\
\hline$A$ & 0.09 & 0.04 & 0.14 & $-0.17^{(a)}$ & 0.50 & 0.67 \\
\hline B & -0.15 & 0.07 & 0.23 & $-0.24^{(a)}$ & 0.32 & 0.56 \\
\hline$c^{(b)}$ & - & - & - & - & - & - \\
\hline D & 0.31 & 0.15 & 0.45 & $0.07^{(a)}$ & 0.56 & 0.63 \\
\hline$E$ & 0.24 & 0.03 & 0.27 & & & \\
\hline $\mathrm{F}$ & $-(b)$ & - & - & $-(d)$ & - & - \\
\hline G & $-0.29^{(a)}$ & 0.40 & 0.69 & 0.06 & 0.11 & 0.17 \\
\hline$H$ & 0.02 & 0.03 & 0.05 & -0.00 & 0.04 & 0.05 \\
\hline I & 0.29 & 0.06 & 0.34 & -0.13 & 0.06 & 0.18 \\
\hline J & 0.33 & 0.11 & 0.44 & 0.15 & 0.12 & 0.26 \\
\hline K & -0.13 & 0.05 & 0.18 & -0.26 & 0.27 & 0.52 \\
\hline \multicolumn{7}{|l|}{ Total } \\
\hline A & $-(c)$ & - & - & $-0.20^{(a)}$ & 0.48 & 0.68 \\
\hline B & -0.08 & 0.23 & 0.32 & -0.27 & 0.31 & 0.58 \\
\hline$c^{(b)}$ & - & - & - & - & - & - \\
\hline $\mathrm{D}$ & $-(c)$ & - & - & $-(c)$ & - & - \\
\hline$E$ & $-(c)$ & - & - & & & \\
\hline$F$ & - (b) & - & - & $-(d)$ & - & - \\
\hline G & $-(c)$ & - & - & 0.02 & 0.10 & 0.12 \\
\hline H & 0.13 & 0.11 & 0.24 & -0.02 & 0.04 & 0.06 \\
\hline I & $-(c)$ & - & - & $-(e)$ & - & - \\
\hline J & $-(c)$ & - & - & 0.12 & 0.11 & 0.23 \\
\hline k & $-(c)$ & - & - & -0.29 & 0.24 & 0.53 \\
\hline
\end{tabular}

(a) Outlier.

(b) Did not participate.

(c) Did not report neutron dose equivalent.

(d) Lost readout due to high fade.

(e) Did not report deep dose. 
TABLE A.3. (continued)

Participant

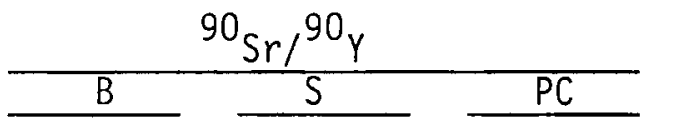

$\frac{X \text { Ray, 58-keV K-F7uorescent }}{\mathrm{B}}-\mathrm{S}$

Shallow

$\begin{array}{lcccccc}\text { A } & -0.30^{(a)} & 0.37 & 0.66 & -0.09 & 0.07 & 0.16 \\ \text { B } & -0.39 & 0.06 & 0.45 & -0.13 & 0.05 & 0.18 \\ C^{(b)} & - & - & - & - & - & - \\ \text { D } & 0.12 & 0.03 & 0.14 & 0.28 & 0.06 & 0.35 \\ \text { E } & 0.14 & 0.12 & 0.26 & 0.44 & 0.11 & 0.55 \\ F & 0.17 & 0.04 & 0.21 & - \text { (b) } & - & - \\ \text { G } & -0.04 & 0.07 & 0.12 & 0.01 & 0.03 & 0.05 \\ \text { H } & - \text { (b) } & - & - & 0.08 & 0.03 & 0.12 \\ \text { I } & -0.26 & 0.18 & 0.44 & 0.28 & 0.12 & 0.40 \\ \text { J } & -0.24 & 0.04 & 0.29 & 0.38 & 0.11 & 0.49 \\ \text { K } & -0.30 & 0.05 & 0.35 & 0.25 & 0.16 & 0.41\end{array}$

Deep

A
B (b)
D
E
F
G
$H$
I
J
K

(a) Out7ier.

(b) Did not participate. 
TABLE A.4. Performance Data (Phase III, JuTy)

\section{Participant}

Sharlow

A

B

$c^{(b)}$

D

E

F

G

H

I

J

K

Deep

B

$c^{(b)}$

D

E

F(c)

G

H

I

J

K

${ }^{137} \mathrm{Cs}$

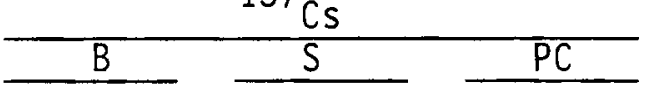

$-0.06$

0.03

$-0.20$

$-0.07$

$-0.12$

$-$

$-0.33$

0.09

$-0.02$

0.02

$-0.38$
0.08

0.02

0.01

0.10

0.06

0.06

0.03

0.06

0.13

0.08

0.01

0.01

0.09

0.10

0.21

0.08

0.18

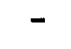

0.32

0.17

0.06

0.08

0.19

0.10

0.21

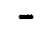

0.08

0.22

0.03

0.07

0.03

0.06

0.05

$\frac{X \text { Ray, HFI }}{\mathrm{B}}-\frac{}{\mathrm{SC}}$

$-0.28$

0.10

0.39

$-0.10$

0.05

0.16

0.10

0.04

0.14

0.01

0.06

0.07

$-0.37$

0.02

0.39

$-0.03$

0.02

0.06

$-0.23$

0.06

0.29

0.14

0.09

0.23

$-0.35$

0.13

0.48 
TABLE A.4. (continued)

Participant

$\frac{X \text { Ray, 16-keV K fluorescent }}{\mathrm{B}-\mathrm{S}}$

${ }^{85} \mathrm{Kr}$
$\mathrm{B}-\mathrm{SC}$

Shallow

$\begin{array}{lcccccc}A & -0.65 & 0.18 & 0.83 & -0.41 & 0.20 & 0.61 \\ B & -0.01 & 0.09 & 0.10 & -1.00 & 0.00 & 1.00 \\ \text { C(b) } & - & - & - & - & - & - \\ \text { D } & -0.14(a) & 0.25 & 0.39 & -0.57 & 0.02 & 0.59 \\ \text { E } & 0.63 & 0.08 & 0.71 & -0.66 & 0.05 & 0.71 \\ F(c) & - & - & - & - & - & - \\ G & 0.64(a) & 0.21 & 0.88 & -0.78 & 0.02 & 0.80 \\ H & -0.42 & 0.05 & 0.46 & -(b) & - & - \\ I & -0.25 & 0.07 & 0.32 & -0.90 & 0.01 & 0.91 \\ J & -0.65 & 0.00 & 0.66 & -0.39 & 0.03 & 0.42 \\ \text { K } & 0.07 & 0.12 & 0.19 & -0.99 & 0.02 & 1.01\end{array}$

Deep

$\begin{array}{lccc}\text { A } & -0.16 & 0.28 & 0.44 \\ B & -0.99 & 0.00 & 1.00 \\ \text { C(b) } & - & - & - \\ \text { D } & 0.12 & 0.05 & 0.16 \\ \text { E } & -0.85 & 0.01 & 0.86 \\ \text { F (c) } & - & - & - \\ G & -1.00 \text { (d) } & - & 1.00 \\ H & -0.57 & 0.03 & 0.60 \\ \text { I } & -0.52 & 0.03 & 0.55 \\ \text { J } & -0.77 & 0.00 & 0.78 \\ \text { K } & -0.54 & 0.04 & 0.58\end{array}$

\footnotetext{
(a) Outlier.

(b) Did not participate.

(c) Readout lost due to high fade.

(d) No deep dose reported.
} 
TABLE A.4. (continued)

\section{Participant}

$\frac{{ }^{90} \mathrm{Sr} /{ }^{90} \mathrm{Y} \text { (PTB) }}{\mathrm{B}-\mathrm{PC}} \stackrel{\text { Moderated }{ }^{252} \mathrm{Cf}}{\mathrm{B}+1} \underline{\mathrm{S} /(\mathrm{B}+1)}$

\begin{tabular}{|c|c|c|c|c|c|}
\hline & Shallow & & & Fast & \\
\hline$A$ & $-0.16^{(\mathrm{a})}$ & 0.08 & 0.24 & 7.9 & 0.21 \\
\hline B & -0.12 & 0.06 & 0.18 & 8.7 & 0.08 \\
\hline C & (b) & - & - & -0.72 & 0.17 \\
\hline$D$ & 0.24 & 0.04 & 0.28 & 21.0 & 0.03 \\
\hline$E$ & 0.46 & 0.09 & 0.54 & 22.2 & 0.02 \\
\hline$F(c)$ & - & - & - & _ & 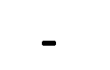 \\
\hline
\end{tabular}

$\begin{array}{lcccrl}G & 0.28 & 0.63 & 0.91 & 10.5 & 0.16 \\ H & -(\mathrm{b}) & - & - & 9.9 & 0.07 \\ I & 0.47 & 0.10 & 0.57 & 13.2 & 0.04 \\ J & 0.53 & 0.12 & 0.66 & 21.5 & 0.05 \\ \mathrm{~K} & -0.05 & 0.04 & 0.09 & 7.4 & 0.11\end{array}$

\begin{tabular}{|c|c|c|}
\hline & B & $S$ \\
\hline & Deep & \\
\hline A & -0.43 & 0.20 \\
\hline & $\begin{array}{r}-0.36 \\
-(d) \\
-(d)\end{array}$ & $\begin{array}{c}0.02 \\
- \\
-\end{array}$ \\
\hline E & 0.14 & 0.15 \\
\hline$F^{(c)}$ & - & - \\
\hline G & -0.47 & 0.03 \\
\hline $\mathrm{H}$ & -0.23 & 0.06 \\
\hline I & $-(d)$ & - \\
\hline J & 0.01 & 0.07 \\
\hline$k$ & -0.55 & 0.04 \\
\hline
\end{tabular}

\footnotetext{
(a) Outlier.

(b) Did not participate.

(c) Readout lost due to high dosimeter fade.

(d) No deep dose reported.

(e) High background. Reported values from two dosimeters given low doses were deleted from the average.
} 
APPENDIX B

SURVEY OF DOSIMETER SYSTEM DESIGNS AND CALIBRATION TECHNIQUES 


\section{APPENDIX B}

\section{SURVEY OF DOSIMETER SYSTEM DESIGNS AND CALIBRATION TECHNIQUES}

The summary of dosimeter system designs and calibration techniques presented in Tables B. 1 and B.2 is useful in identifying parameters associated with good dosimeter performance. Beta-gamma dosimeters are identified as film or TLD. The holder filtration for the shallow and deep dose elements is indicated and calibration energies are summarized. Several participants calibrated to additional photon energies and incorporated corrections for dosimeter energy dependence in the dose calculation. TL neutron dosimeters are identified by the geometry of the absorber. For example, any design utilizing neutron-sensitive and neutron-insensitive TLDs surrounded by $30 \mathrm{mi} 1$ of cadmium is referred to as a Hankins dosimeter. 
TABLE B.1. Participant Summary of Beta-Gámma Dosimetry Practices

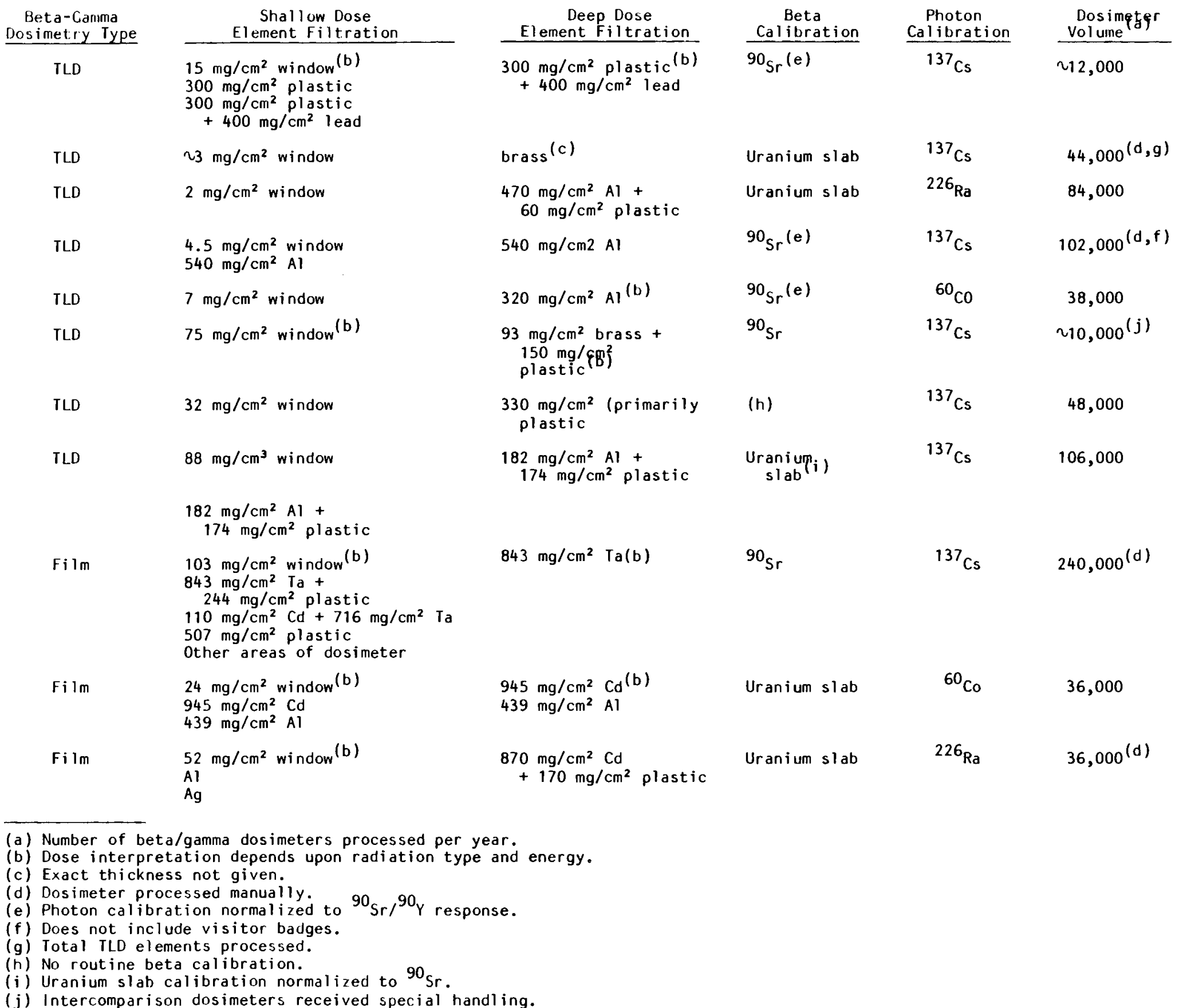


TABLE B.2. Participant Summary of Neutron Dosimetry Practices

Neutron

Dosimeter

Design

$T L D(c)$

Dose Interpretation

TLD $(c)$

Total neutron dose

PuBe

$\frac{\begin{array}{c}\text { Dosimeter } \\ \text { Volume }\end{array}}{\sim 1,000^{(d)}}$

$\operatorname{TLD}(c)$

Total nuetron dose

Unmoderated ${ }^{252} \mathrm{Cf}$

$\sim 100,000^{(d)}$

Unmoderated ${ }^{252} \mathrm{Cf}$

840

TLD $(c)$

Total neutron dose

Unmoderated ${ }^{252} \mathrm{Cf}$

$>100,000$ thermal neutron dose

$T L D(e)$

Total neutron dose

PuF

$12,000^{(d)}$

$\operatorname{TLD}^{(f)}$

Total neutron dose

Unmoderated ${ }^{252} \mathrm{Cf}$

12,000

$T L D(g)$

Total neutron dose

Unmoderated ${ }^{252} \mathrm{Cf}$

$44,000^{(d)}$

$T L D(g)$

Total neutron dose

Unmoderated ${ }^{252} \mathrm{Cf}$

$\sim 10,000$

TLD $(h)$

Fast neutron dose thermal neutron dose

Unmoderated ${ }^{252} \mathrm{Cf}$

(normalized to field calibration) sigma pile (thermal)

$\operatorname{TLD}^{(i)}$

Total neutron dose

Unmoderated ${ }^{252} \mathrm{Cf}$

38,000

NTA film ${ }^{(h)}$ Fast neutron dose PuBe

(a) Calibration initially used to interpret neutron dose for the intercomparison. Calibrations used to interpret occupational dose to personnel may differ from the intercomparison calibrations.

(b) Number of neutron dosimeters processed per year.

(c) Hankins design (TLDs enclosed in 30 mils cadmium).

(d) Dosimeters read manually.

(e) Hoy dosimeter (TLDs at two depths in polyethylene with cadmium surrounding the dosimeters).

(f) No neutron absorber used in dosimeter.

(g) Elements shielded in front by cadmium and elements shielded in back by cadmium.

(h) Elements shielded in front by cadmium and elements unshielded by cadmium.

(i) Elements shielded in front by boron and elements unshielded by boron.

(j) Neutron dosimeters used only in special circumstances. 


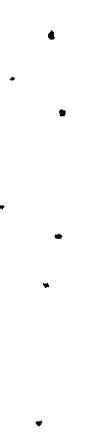




\section{APPENDIX C}

ANSI N13.11 AS A PERSONNEL DOSIMETER PERFORMANCE STANDARD FOR DOE LABORATORIES 


\section{APPENDIX C}

\section{ANSI N13.11 AS A PERSONNEL DOSIMETER PERFORMANCE STANDARD FOR DOE LABORATORIES}

The purpose of draft ANSI N13.11 ("Criteria for Testing Personnel Dosimetry Performance") is "to provide a procedure for testing routine personnel dosimetry performance under controlled conditions of dosimeter irradiation..." (ANSI 1983). The standard includes specifications for the number of dosimeters, the radiation categories and dose-equivalent ranges, the types of radiation sources and irradiation geometries and the performance criteria to be applied to the test results. ANSI N13.11 was written to apply to a general audience of large and small dosimetry processors (ANSI 1983). The performance tests were designed to be both generally applicable and inexpensive. Explicitly stated is the intention of not immediately failing a large number of commercial processors. As such, the standard does not necessarily meet the needs of DOE facilities.

The results of performance testing of DOE laboratory personnel dosimetry systems were used to evaluate the standard. Conclusions of the evaluation are that: 1) the performance algorithm is not the optimal choice for implementing a performance standard; 2) the design of the beta category can lead to ambiguous results; 3 ) additional performance categories are required for a sufficient performance evaluation; and 4) the conversion factors from exposure to dose for low-energy photons used in the standard are inconsistent with the irradiating geometry and require further study. These topics are discussed below.

\section{C.1 THE PERFORMANCE ALGORITHM}

The performance algorithm specified in ANSI N13.11 is based on the 1 imitations of present measurement techniques using personnel dosimeters (ANSI 1983, Appendix D3). Recommendations on the accuracy of reported doses in ICRP Report No. 20 (ICRU 71) and NCRP Report No. 57 (NCRP 78) are quoted in Appendix D3, but only indirectly used. The algorithm was changed after the results of the 
pilot study on dosimeter testing was published. The number of dosimetry processors passing the tests in the pilot study almost doubled when re-evaluated using the present algorithm. The apparent concern of the working group responsible for the development of the standard was not to fail too many existing commercial processors. The algorithm specified is statistically analyzed to obtain the effective standard of performance indicated, and alternate algorithms are explored.

The algorithm specified in ANSI N13.11 is

$$
|B|+S \leq L
$$

where the tolerance level, $L$, is 0.5 for the protection categories; the bias (B) is

$$
B=\frac{1}{n} \sum_{i=1}^{n} P_{i} ;
$$

the standard deviation $(S)$ is

$$
S=\left[\frac{1}{n-1} \sum_{i=1}^{n}\left(P_{i}-B\right)^{2}\right]^{1 / 2} ;
$$

the performance quotient for the $i^{\text {th }}$ dosimeter $\left(P_{i}\right)$ is

$$
P_{i}=\frac{\text { Reported }(i)-\text { Delivered }(i)}{\text { Delivered }(i)}
$$

and

$$
n=15
$$

\section{C.1.1 Estimation Uncertainties for the Bias and Standard Deviation}

Significant estimation uncertainties are caused by the use of a low number of dosimeters per test. A reasonable confidence limit was chosen to prevent frequent retests due to statistical fluctuations. A 5\% probability of failure in each test implies an approximately $35 \%$ probability of failure in one of the 9 tests for the protection categories. Thus, we assumed a $95 \%$ confidence-of-passing limit for the calculations, even though the tests are correlated. 
The estimation of true performance parameters required the assumption that the data follows a definite probability distribution. We assumed that the 15 reported dose equivalents (per category) come from a normal distribution about a single mean. This is not the case for several reasons, but is probably an adequate approximation.

For $95 \%$ of the samples the magnitude of the bias is approximately bounded by:

$$
|B|<\left|\bar{P}_{t}\right|+\frac{Z_{\alpha}}{\sqrt{15}}\left(1+\bar{P}_{t}\right) \sigma_{t},
$$

where $P_{t}$ and $\sigma_{t}$ are the true mean performance quotient and the true (zerobias) standard deviation and $Z_{\alpha}$ is the probability-distribution value which is exceeded for $\alpha=5 \%$ of the samples. For the case $\left|P_{t}\right|<\sigma_{t}$, a onesided normal distribution can be used for which $Z_{\alpha}=1.6$. For $\left|P_{t}\right|=0$, the $Z_{\alpha}$ value is upper bounded by the two-sided normal distribution $\left(z_{\alpha}<2.0\right)$.

For $95 \%$ of the samples the standard deviation is approximateiy bounded by:

$$
S<1.30\left(1+\bar{P}_{t}\right) \sigma_{t},
$$

using a $x^{2}$ distribution with fourteen degrees of freedom. Because the uncertainties in $B$ and $S$ are independent for normally distributed data, a close approximation can be obtained for the performance criterion using propagation of errors:

$$
\begin{aligned}
{[|\mathrm{B}|+S]_{\max } } & =\left[\left|\bar{P}_{t}\right|+\left(1+\bar{P}_{t}\right) \sigma_{t}\right]_{\max } \\
& +\left\{\left(\frac{Z_{\alpha}}{\sqrt{15}}\right)^{2}+(0.30)^{2}\right\}^{1 / 2}\left(1_{t}+P_{t}\right) \sigma
\end{aligned}
$$

with $|\mathrm{B}|+\mathrm{S} \leq 0.5$ for approximately $95 \%$ of the samples. The true performance criterion is: 


$$
\begin{aligned}
& {\left[\left|\bar{P}_{t}\right|+\left(1+\bar{P}_{t}\right) \sigma_{t}\right] \leq} \\
& 0.5-\left\{\left(\frac{z_{\alpha}}{\sqrt{15}}\right)^{2}+(0.30)^{2}\right\}^{1 / 2}\left(1_{t}+P_{t}\right) \sigma
\end{aligned}
$$

Note that the contribution to the uncertainty from the bias is greater than the contribution from the standard deviation.

To evaluate the uncertainties, we used estimates of the standard deviations from the test data. Table C.1 lists the estimated mean and range of standard deviations. Data with large standard deviations due to significant, identified problems were excluded. The mean values range from 0.08 to 0.18 . Fluctuations which were still representative of the group went as high as 0.3 for the neutron tests.

\begin{tabular}{|c|c|c|}
\hline Exposure Source & \multicolumn{2}{|c|}{$\begin{array}{l}\text { Estimate of }[S /(1+B)]^{(a)} \\
\text { Mean }\end{array}$} \\
\hline${ }^{137} \mathrm{Cs}$ & 0.08 & $0.04-0.15$ \\
\hline$X$ ray & 0.10 & $0.05-0.21$ \\
\hline${ }^{137} \mathrm{Cs} / \mathrm{X}$ ray & 0.13 & $0.04-0.26$ \\
\hline${ }^{90} \mathrm{Sr}$ & 0.14 & $0.05-0.23$ \\
\hline${ }^{137} \mathrm{Cs} /{ }^{90} \mathrm{Sr}$ & 0.14 & $0.04-0.30$ \\
\hline${ }^{252} \mathrm{Cf}$ & 0.18 & $0.13-0.30$ \\
\hline
\end{tabular}

TABLE C.1. Estimates of (Zero-Bias) Standard Deviations

(a) Estimates made from dosimeter performance data for DOE laboratories.

In Table C.2, we present the estimated maximum true performance quotients and performance criteria for the appropriate range of standard deviations. Note that: 
TABLE C.2. Maximum True Performance Values (95\% Probability of Passing)

\begin{tabular}{|c|c|c|c|c|c|}
\hline \multirow[b]{2}{*}{$\sigma_{t}$} & \multicolumn{2}{|c|}{ Positive Bias } & \multicolumn{2}{|c|}{ Negative Bias } & \\
\hline & $\begin{array}{l}\text { Maximum } \\
\text { Performance } \\
\text { Quotient }\end{array}$ & $\begin{array}{c}\text { Maximum } \\
\text { Performange } \\
\text { Criteria } \\
\end{array}$ & $\begin{array}{l}\text { Maximum } \\
\text { Performanceg } \\
\text { Quotient }\end{array}$ & $\begin{array}{l}\text { Maximum } \\
\text { Performan }(5) \\
\text { Criteria }\end{array}$ & $\begin{array}{l}Z \\
\text { User }\end{array}$ \\
\hline 0.08 & 0.34 & 0.44 & -0.43 & 0.48 & 6 \\
\hline 0.20 & 0.15 & 0.38 & -0.28 & 0.43 & 6 \\
\hline 0.30 & 0.02 & 0.32 & -0.04 & 0.34 & 0 \\
\hline
\end{tabular}

(a) $\left|P_{t}\right|$ maximum.
(b) $\left[\left|P_{t}\right|+\left(1+P_{t}\right) \sigma_{t}\right]$ maximum.

- With a true standard deviation of 0.3 , the category is nearly impossible to pass for $95 \%$ of the samples; the bias has to be finely adjusted.

- With a small standard deviation the bias can rise to 0.4 and still meet the $95 \%$ pass requirements.

- The advantage of a negative bias is apparent for the mid-range of the standard deviation $\left(\sigma_{t}=0.20\right)$. In this case, the optimum setting for the bias is -0.07 .

Some dosimeter systems have response differences for high- and low-energy photons. For a standard deviation of less than $10 \%$, the allowed high/lowenergy response difference is $+0.3 /-0.4$, or better than a factor of two. For a standard deviation near $20 \%$, the allowed response difference is $+0.2 /-0.3$, or a factor of 1.7. While this allows considerable leeway in dosimeter response, the performance test could require an intentional miscalibration for ${ }^{137} \mathrm{Cs}$ of up to $-40 \%$ to allow passing $x$-ray categories.

\section{C.1.2 Alternate Performance Algorithms}

Even though the bias and standard deviation were explicitly separated in the aigorithm to aid in diagnosing the problems, the standard deviation shifting with the bias can mislead the diagnosis. Two possible solutions are: 
1) diagnose using the quantities $B$ and $S /(1+B)$, or 2$)$ rewrite the algorithm in the form:

$$
|B|+\frac{S}{1+B} \leq L
$$

This formula no longer has a significant advantage for negative bias. A disadvantage is that there is an increase in the uncertainty due to the use of the small number of dosimeters.

To design other algorithms, it is important to retain simplicity and to make diagnosis of problems as straightforward as possible. The N13.11 standard does not explicitly state the intention of the performance algorithm. Appendix D3 says that 1) they will follow the recommendations of ICRU No. 20 (1971) and NCRP Report No. 57 (1978), which place a 30\% limit on the uncertainty near the maximum permissible dose equivalent; and 2) because lower dose equivalents are treated the same as higher dose equivalents, we can apply the $30 \% 1$ imit to all dose levels. What is not specified is the number of dosimeters or the time interval allowed to achieve this $30 \%$ accuracy. ICRU No. 20 implies this level for each person.

Table C. 3 lists several possible algorithms based on assumed criteria. The first column gives the criteria, the second gives the number of dosimeters used to formulate the statistics and the last gives the implied algorithm. The form $|B|+C \cdot S \leq L$ originates from the desire to have the dose equivalent reports be less than the tolerance limit for greater than a specified percent of the samples. As can be determined from the table, the present algorithm is a little more stringent than requiring four dosimeters to be within the tolerance limit for $95 \%$ of the samples.

Requiring that the average of all of a processor's reports be less than $L$ results in the elimination of $S$ from the algorithm (row 4). This by itself is unacceptable because an individual's report must have some validity. Placing independent limits on the bias and standard deviation has some advantages. Table C. 4 contains the maximum true parameters for independent algorithms. The bias has a 1 imit of $25 \%$ and the normalized standard deviation has a limit of $40 \%$. The maximum true calibration bias decreases with increasing standard deviation, but not at the strong pace of the current algorithm. The maximum 
TABLE C.3. Performance Algorithms

\begin{tabular}{|c|c|c|}
\hline Criteria & $\begin{array}{c}\text { Number } \\
\text { of Dosimeters } \\
\end{array}$ & $\frac{(\mid \mathrm{Blgorithm}(\mathrm{a})}{\mathrm{B} \mid+\mathrm{C} \cdot \mathrm{S} \leq \mathrm{L}}$ \\
\hline $\begin{array}{l}\text { Each dosimeter } \\
\leq L(95 \%)\end{array}$ & 1 & 1.6 \\
\hline $\begin{array}{l}\text { Annual report } \\
\leq L(95 \%) \\
\text { Quarterly reports } \\
\text { Monthly reports }\end{array}$ & $\begin{array}{r}4 \\
12\end{array}$ & $\begin{array}{l}0.8 \\
0.5\end{array}$ \\
\hline Lifetime report $\leq L$ & Large & 0.0 \\
\hline
\end{tabular}

(a) A one-sided normal distribution is assumed. This is approximately valid if $S \_B$. If $S$ is large, " $c$ " should be increased.

TABLE C.4. Independent Testing

$\begin{array}{lccc} & |B|<0.25 \\ \frac{\sigma_{t}}{0.08} & \frac{\left|P_{t}\right|_{\max }}{0.21} & \frac{\left(\left|P_{t}\right|+\sigma_{t}\right)_{\max }}{0.29} & \\ 0.2 & 0.16 & 0.36 & (1+B)<0.4 \\ 0.3 & 0.12 & 0.42 & \end{array}$

true bias plus standard deviation is about 30\% for low-variance categories (agrees with the spirit of ICRU No. 20) and is about $40 \%$ for the largest acceptable standard deviation $\left(\sigma_{t}=0.3\right)$. This algorithm has the advantage of requiring a good calibration for all categories without automatically failing the higher-variance categories. Ideally each category would have a different limit on the standard deviation which would be related to state-ofthe-art precision. The two-test algorithm is a tougher test to pass for the processor who uses a dosimeter with a large photon energy dependence to measure dose equivalents for beta, $x$-ray, and ${ }^{137}$ Cs sources. Because the flexibility to put all three calibrations near zero is not always allowed by the dosimeter design, a compromise is reached. The latitude available to compromise beta/photon calibration biases decreases from about $\pm 35 \%$ to $\pm 20 \%$. 


\section{C.1.3 Conclusions}

Using the present performance algorithm for a 15-dosimeter test produces several side effects which complicate the test analysis and do not meet the tolerance levels recommended by the IRCU and the NCRP. These are:

- The standard deviation of the dosimeter population is the most sensitive parameter of the test. Efforts to reduce it pay in increased ability to predict test results. Neutron dosimeters are most likely to have a problem.

- The standard deviation is correlated with the calibration bias, which complicates the performance analysis.

- For large standard deviations $(<0.2)$, a careful adjustment of the calibration bias (to better than 0.10 ) will be beneficial. A bias of -0.07 is preferred for standard deviations of $\sim 0.2$.

- The performance test discourages the conservative practice of calibrating to ${ }^{137} \mathrm{Cs}$ and accepting an overresponse of the LiF phosphor to $x$ rays. A shift in the calibration bias to $<-0.25$ for ${ }^{137}$ Cs may be required to pass many existing dosimeter designs.

The current algorithm is reasonable from a fundamental standpoint. However, the tolerance limit is greater than the 1 imit recommended by ICRU Report No. 20 and NCRP Report No. 57. It is stated in Appendix D3 of the ANSI document that a greater tolerance value was required because of design 1 imits of current dosimeters. In the statistical analysis it was found that the greater limit is required because of variability of test results when using only 15 dosimeters. The conclusions are that 1 ) when using a low number of dosimeters in a test situation, independent testing of the bias and standard deviation allow better control for meeting recommended tolerance levels and removes several unpleasant side effects in the algorithm; and 2) combined testing agrees with the spirit of recommended monitoring guidelines, but requires larger numbers of test dosimeters for the statistical analysis. 


\section{C.2 DESIGN OF THE BETA CATEGORY}

The specifications for the set up of the ${ }^{90} \mathrm{Sr} /{ }^{90} Y$ source are insufficient to guarantee reproducible irradiations in current dosimeters. Two dosimeter processors obtaining irradiations at the PNL and another laboratory using irradiations designed to meet ANSI N13.11 requirements quote differences of $15 \%$ and $35 \%$ in response. The cause is probably related to the composition of electron energies and angles arriving at the irradiation position. It may be necessary to quote relative depth-dose response criteria at the irradiation position to help achieve reasonable reproducibility between laboratories.

\section{3 REQUIREMENTS FOR ADDITIONAL PERFORMANCE CATEGORIES}

Testing for dosimeter performance using ${ }^{90} \mathrm{Sr} /{ }^{90} \mathrm{Y}$ is not adequate for determining performance under field conditions. The most prevalent mean energies in the work place are much less than the mean energy of the ${ }^{90} \mathrm{Sr} /{ }^{90} \mathrm{Y}$ source. Most dosimeters are highly energy dependent because of the thickness of the sensitive element and of the overlying window (see Section 4.5). Only one beta energy was chosen by the working group which developed ANSI N13.11 to avoid failing a large number of processors. The ${ }^{90} \mathrm{Sr} /{ }^{90} \mathrm{Y}$ source had the advantage of being readily available and at high enough energy to penetrate the popular 0.9-mm TLD-700 (LiF) chip. The result is a beta category which allows passing responses for dosimeters which underrespond by better than a factor of five to beta particles with $0.7 \mathrm{MeV}$ maximum energy. The filtered ${ }^{90} \mathrm{Sr} /{ }^{90} \mathrm{Y}$ source has a maximum energy of approximately $2 \mathrm{MeV}$. An acceptable choice for a second source would be ${ }^{204} \mathrm{Tl}$ with $0.76 \mathrm{MeV}$ maximum energy.

The current draft of ANSI N13.11 specifies a test using a mixed field of photons and heavy-water moderated ${ }^{252} \mathrm{Cf}$ neutrons. A second neutron test was not included in the standard because current neutron dosimeters have a large energy dependence. Another category with a different neutron energy will be desirable when less energy-dependent dosimeter designs are available. However, it would be beneficial to test current designs for variability (or standard deviation) at a higher energy and to roughly quantify the energy dependence. 


\section{C.4 CONVERSION FACTORS FROM EXPOSURE TO DOSE EQUIVALENT FOR}

LOW-ENERGY PHOTONS

The exposure-to-dose-equivalent conversion factors for low-energy photons ( $C_{x}$ factors) listed in draft ANSI N13.11 were derived by Dimbylow and Francis (1979) for the four-element ICRU sphere using Monte-Carlo calculations. For the dosimeter performance tests, the dosimeters are mounted on a slab phantom of methylmethacrylate. The dosimeters are designed to monitor for dose to tissue of the body on which they are mounted. However, the performance tests require that they monitor for dose to the ICRU sphere while mounted on a slab phantom. This results in the miscalibration of even the ideal personnel dosimeter. The choice of the phantom shape for the specification of $C_{x}$ factors is not arbitrary, as has been argued (Ehrlich 1982).

The size and shape of the phantom or person is important for monitoring low-energy photons because radiation is scattered back to the surface from the body. Backscatter can contribute an additional $40 \%$ to $50 \%$ to the dose at the surface for photon energies between 60 and $100 \mathrm{keV}$ (Johns and Cunningham 1978). The dosimeter ideally would be able to properly record the level of backscattered radiation and, thus, approximately compensate for fluctuations dependent on the size of the person. Calibrating the dosimeter with the slab geometry and specifying the dose using spherical geometry results in a miscalibration of the dosimeter.

The contribution to the dosimeter due to backscattered radiation is different for the slab and spherical phantoms. Nelson and Chilton (1982) used Monte-Carlo calculations to derive the $C_{x}$ factors for the slab geometry with the ICRU four-element composition. Their results agreed closely with the calculations of Dimbylow and Francis (spherical geometry) below $50 \mathrm{keV}$, but were $20 \%$ higher between $80 \mathrm{keV}$ and $100 \mathrm{keV}$. This difference accounts for the major discrepancy between the $C_{x}$ factors specified in ANSI N13.11 (spherical geometry) and the available direct measurements (slab geometry, yoder et al. 1979). Nelson and Chilton also performed calculations for the tissueequivalent plastic used by Yoder, et al. (1979), for direct measurements of $C_{x}$ factors using the slab geometry. The significant difference between the calculations for the Yoder plastic and the measurements was at energies below 
$20 \mathrm{keV}$. The difference was attributed to a high-energy contamination in the K-fluorescent spectra used by Yoder, et al.

There may also be significant errors at lower energies due to the absence of trace elements in the ICRU sphere. A personnel dosimeter is expected to respond in a tissue-equivalent manner. Fully tissue-equivalent $C_{x}$ factors (including trace elements) are required to test dosimeters for proper response. The tissue-equivalent plastic used by Yoder, et al. responds closer to tissue with trace elements than the four-element composition; it does not respond sufficiently close to be considered equivalent to tissue with trace elements (Nelson and Chilton 1982; Ehrlich 1982). The effects of using methylmethacrylate for the testing phantom (as specified in ANSI N13.11) has not been evaluated.

REFERENCES

American National Standards Institute (ANSI). 1983. American National Standard, Criteria for Testing Personnel Dosimetry Performance. ANSI N13.111983. New York, New York.

Dimbylow, P. J., and T. M. Francis. 1979. A Calculation of the Photon DepthDose Distributions in the ICRU Sphere for a Broad Parallel Beam, a Point Source and an Isotropic Field. National Radiological Protection Board, NRPB 92, Harwe11, England.

Ehrlich, M. 1982. "Choice of Conversion Factors to the Shallow and Deep Dose Equivalent for Use in a U.S. Personnel Dosimetry Performance Testing Preogramme." Radiation Protection Dosimetry, 1(4):271-275.

International Commission on Radiation Units and Measurements (ICRU). 1971. Radiation Protection Instrument and Its Application. Report No. 20. Washington, D.C.

Johns, E. F., and J. R. Cunningham. 1978. The Physics of Radiology. Charles C. Thomas Publishing, Springfield, Illinois.

National Council on Radiation Protection and Measurements (NCRP). 1978. Instrumentation and Monitoring Methods for Radiation Protection. Report No. 57. Washington, D.C.

Nelson, R. F., and A. B. Chilton. 1982. "Depth Doses in Slab Phantom for Low Energy Monoenergetic Photons." Radiation Protection Dosimetry, 1(4):285-289.

Yoder, R. C., et al. 1979. Confirmation of Conversion Factors Relating Exposure and Dose-Equivalent Index Presented in ANSI N13.11. NUREG/CR-1057, PNL-3219, Pacific Northwest Laboratory, Richland, Washington. 

APPENDIX D

PARTICIPANT COMMENTS 
APPENDIX D

\section{PARTICIPANT COMMENTS}

Comments were received from the participants during the testing and after the review of this document. Notable comments are summarized below:

1. Comment: The response to ${ }^{90} \mathrm{Sr} /{ }^{90} \mathrm{Y}$ sources varied significantly comparing results of this test to the results of the pilot study evaluation of ANSI N13.11.

Answer: This effect was found to be real. See Appendix C.2.

2. Comment: Film dosimeters were not returned in the shipping box containing the appropriate desiccant. Signal fading voided the results.

Answer: The people handling the dosimeters were not properly trained for the special needs of some film dosimeters.

3. Comment: TLD fading may have been significant over the course of testing.

Answer: This effect was not investigated. Unfortunately the somewhat haphazard arrival of participant dosimeters and the unavailability of some exposure system consideraly lengthened the dosimeter turn around rate.

4. Comment: Although our film dosimeter failed the low energy photon and. gamma plus low energy categories in Phases I and II, this was due to calibration and evaluation errors, as was shown in Phase III. While it will eventually be necessary to abandon film dosimetry for other reasons, we do not agree that $T L$ dosimeters are intrinsically superior for low energy photon dosimetry. 
:

$\therefore$ 


\section{$\underline{\text { DISTRIBUTION }}$}

No. of

Copies

OFFSITE

5 E. J. Vallario

Senior Health Physicist

DOE Division of Operational and

Environmental Safety

Washington, DC 20545

27 DOE Technical Information Center

R. E. Alexander

Pantex Plant

P. 0. Box 30020

Amari110, TX 79177

J. R. Cortez

Los Alamos National Laboratory

Box 1663, MS 692

Los Alamos, NM 87545

S. L. Crain

Monsanto Research

Mound Facility

Miamisburg, $\mathrm{OH} 45432$

J. P. Cusimano

RESL-CF690

U.S. Department of Energy

550 Second Street

Idaho Falls, ID 83401

E. H. Dolecek

Argonne National Laboratory

OHS/HP Bldg. 14

9700 S. Cass Avenue

Argonne, IL 60439

J. H. Elliott

Lawrence Livermore National

Laboratory

P.0. Box $5505 \quad L-383$

Livermore, CA 94550
No. of

Copies

R. B. Falk

Rockwell International

Rocky Flats Plant

P.0. Box 464

Golden, CO 80401

R. M. Hall

735-A

Savannah River Plant

E. I. DuPont deNemours \& Company

Aiken, SC 29801

K. L. (Holbrook) Jones

265 El Dorado Blvd.

No. 713

Webster, TX 77598

J. H. P. Lawrence

Group $\mathrm{H}-1, \mathrm{MS}-401$

Los Alamos National Laboratory

Los Alamos, NM 87545

L. Phillips

Brookhaven National Laboratory

Bldg. 535A

Upton, NY 11973

T. J. Powel1

Lawrence Livermore National Laboratory

P.0. Box $5505 \quad L-383$

Livermore, CA 94550

D. J. Thompson

Radiation Dosimetry

Division 3313

Sandia National Laboratories

P.0. Box 5800

Albuquerque, NM 87185

R. B. Schwartz

Bldg. 235

National Bureau of Standards

Washington, DC 20234 
No. of

Copies

B. P. Smith

Reynolds Electic \& Engineering Co., Inc.

P.0. Box 14400 MS-708

Las Vegas, NV 89114

E. Storm

Los Alamos National Laboratory

Box 1663 MS-692

Los Alamos, NM 87545

C. Swezey

Brookhaven National Laboratory

Bldg. 535A

Upton, NY 11973

I. J. Wells

Reynolds Electric \& Engineering Co., Inc.

P. 0. Box 14400 MS -708

Las Vegas, NV 89114

R. C. Yoder

R. S. Landauer, Jr., \& Co.

Glenwood Science Park

Glenwood, IL 60425
No. of

Copies

ONSITE

1 DOE Richland Operations Office

H. E. Ransom/P. K. Clark

30 Pacific Northwest Laboratory

W. J. Bair

T. H. Essig

L. G. Faust

J. J. Fix

R. A. Fox

W. A. Glass

R. T. Hadley

G. R. Hoenes

R. T. Hogan

C. D. Hooker

J. C. McDonald

J. L. Pappin

P. L. Roberson (10)

J. M. Selby

Technical Information (5)

Publishing Coordination (2) 